\title{
Simulating the Principal-Agent Relationship between Enterprise Owners and Professional Managers Using Evolutionary Game Theory and System Dynamics
}

\author{
Liang Yuan (iD, ${ }^{1}$ Xiaorui Tao ${ }^{(D)},{ }^{1}$ Thomas Stephen Ramsey $\left(\mathbb{D}^{1}{ }^{1}\right.$ \\ and Dagmawi Mulugeta Degefu $\mathbb{D}^{1,2}$ \\ ${ }^{1}$ College of Economics and Management, China Three Gorges University, Yichang 443002, China \\ ${ }^{2}$ Faculty of Engineering and Architectural Science, Ryerson University, Toronto M5B 2K3, Canada \\ Correspondence should be addressed to Xiaorui Tao; xiaorui.tao@foxmail.com
}

Received 12 April 2021; Revised 20 June 2021; Accepted 1 July 2021; Published 17 July 2021

Academic Editor: Abdelalim Elsadany

Copyright (c) 2021 Liang Yuan et al. This is an open access article distributed under the Creative Commons Attribution License, which permits unrestricted use, distribution, and reproduction in any medium, provided the original work is properly cited.

\begin{abstract}
The separation of ownership and management is a common operation mode in modern enterprises, which establishes the principal-agent relationship between modern enterprise owners and professional managers. Due to the information asymmetry and interest conflicts between the principal and agent, the principal-agent problem will occur and affect the efficiency of enterprise operations. Therefore, it is necessary to propose measures to improve the principal-agent relationship. This paper analyzed the principal-agent problem between enterprise owners and professional managers based on system dynamics, evolutionary game, and principal-agent theory and built a principal-agent evolutionary game model to analyze the rule of strategic choices and predict the equilibrium outcomes of different scenarios. In addition, the influence of different factors on strategic choices was simulated by the system dynamics model. The results depicted that the basic benefits and costs of cooperation are the key factors of the strategic choices, and the gap between the expected payoffs of different strategies also affects the probability of choosing those cooperative strategies. Proper supervision, standardization of the managerial labor market, and establishment of long-term incentives are crucial to cooperation between enterprise owners and professional managers.
\end{abstract}

\section{Introduction}

In the modern economic market, the sustained, stable, and healthy development of enterprises is closely related to the national economy and people's livelihood. In order to adapt to the increasingly complex market environment, the enterprise owners introduce professional managers and use their mature management experience to provide support for the enterprise's operation $[1,2]$. However, the quality of professional managers varies greatly in the managerial labor market, cases of failure in the employment of professional managers by enterprises occur constantly, and agency problems cause the development of enterprises to fall into deadlocks $[3,4]$. Due to the different interest demands and asymmetric information, professional managers may take speculative behavior against the intention of the principal, causing the agency problem of moral hazard [5]. Hence, it is a major theoretical and practical issue facing the sustainable development of modern enterprises to improve the principal-agent relationship of enterprises and realize a win-win cooperation between both parties. To solve the agency problem, many scholars researched it mainly based on the principal-agent model, experimental simulation, and game model where these studies have important reference significance for the research of the principal-agent relationship.

First, since the principal-agent theory has developed into a mature theoretical system, using its theoretical model can intuitively reflect the respective utility functions of both parties and find the optimal solution to maximize the utility. Many scholars constructed and applied different principalagent models to solve the problem of information asymmetry in the principal-agent relationship. There are three 
basic models applied to the principal-agent problem [6]: The first one is the state-space formulation method, which is proposed by Wilson [7] and further improved by Spence and Zeckhauser [8] and Ross [9]. The second one is the parameterized distribution formulation method originally constructed by Mirrless [10] and developed by Holmstrom [11], which is widely used and has become a standardized approach [12]. The third one is the general distribution formulation method proposed by Gilboa and Schmeidler [13], which clearly describes the model without a complex explanation of the agent's actions and costs. With the continuous development of information economics, the principal-agent model has gradually been developed. Rasul and Sonderegger [14] introduced external transaction factors, combined with the principal-agent model to analyze the agent's external transaction selections. Silvers [15] and Helm and Wirl [16] established a principal-agent model with moral hazard and discussed the contractual issues in the principal-agent problem of asymmetric and public information. Bichler and Paulsen [17] and Uğurlu [18] explored the incentive problem through the development of a model with the assumption that the principal and agent are riskaverse. Chaney [19] examined the principal-agent cooperative relationship and proposed how to establish effective incentive contracts from the perspective of principal-agent theory. Schosser [20], Sun et al. [21], and Chang [22] found that designing the optimal incentive contract is the key to resolve the conflicts of interest between principal and agent. Wang et al. [23] proposed to introduce the time preference into the principal-agent model which provided useful references for solving the agency problem.

Second, the experimental simulation method can adjust the procedures according to the performance characteristics of the participants, thereby obtaining a more precise and concise result [24]. Many scholars have used experimental simulations to examine the factors motivating managers to work conscientiously and explore the optimal contract for principal-agent. Keser [25] studied behaviors in a principalagent situation with moral hazard and evaluated the effect of principal-agent theory on the relationship. Leopold-Wildburger and Mietek [26] discussed the impact of information asymmetry on compensation and explored the relationship between salary incentives and the degree of effort of the agent. Corgnet et al. [27] constructed a principal-agent model with reference-related utility and proved that the labor contract with weak monetary incentives and wageindependent goals is necessary to solve the principal-agent problem. Flannery and Roberts [28] found that nonmonotonic contracts with incentives are more conducive to resolving the principal-agent problem. Rubin and Sheremeta [29] and Rud et al. [30] discussed the influence of competition on the moral hazard in the principal-agent relationship and pointed out the role of managerial labor market on personal incentives and equilibrium results.

Third, since the principal and agent are rational decision-makers, both parties will make beneficial strategic choices to maximize their payoffs and balance the interests of other stakeholders. Game theory can explore the characteristics and rules of the behavior selection of stakeholders
[31].Therefore, it is widely used to analyze principal-agent problems. Gong et al. [32] and Azar and Micali [33] constructed the principal-agent game model under the conditions of symmetric and asymmetric information and clarified the design principles of the incentive mechanism through the analysis of the optimal solution. Kellner [34] introduced the ambiguity aversion into the principal-agent model and studied the effective incentives of managers, which provided references for enterprises to design the incentive mechanism. Páez-Pérez and Sánchez-Silva [35] and Kadan et al. [36] studied the mechanism of manager's speculative behaviors based on the game model and suggested that owners should improve the efficiency of supervision to restrain improper behavior. $\mathrm{Ni}$ et al. [37] used the game model to analyze the influence of incentives on principal-agent contracts and game equilibrium.

Most of these past studies focused on analyzing the causes of principal-agent problem, the role of transaction cost and risk preference, and proposing to establish an incentive mechanism to restrain the behavior of both parties. However, the root cause of the principal-agent problem is the contradiction between the principal and agent due to the difference of interest preference under asymmetric information; the following characteristics and factors need to be considered when studying the principal-agent relationship. In the cooperation and competition of modern enterprises, the two parties involved in the principal-agent relationship are different groups and play different roles in the operation of companies. There are obvious differences in the interests of the two parties in many aspects such as ownership of property rights and responsibilities where both parties involved making strategic choices based on the principle of maximizing their benefits leading to conflicts [38]. Furthermore, the asymmetric information and the limited rationality of participants caused by the complexity of the principal-agent relationship are obvious as both parties involved in the game are bounded rational stakeholders and cannot collect complete information [39]. The two parties involved in the game will adjust their strategic choices, which is a process of dynamic and constant change. Therefore, it is necessary to analyze the trend and rule of strategic choices of both parties during the decision-making process, and evolutionary games as a natural study approach could apply to analyze the behavior change of the principals and agents involved over time.

Moreover, it is very important to analyze the dynamic evolution process of principal-agent relationship from the quantitative perspective to improve the management efficiency. System dynamics is a computer simulation method for studying information feedback loops of complex systems. Not only can it properly describe the complicated issue of the principal-agent relationship, but it also can provide a comprehensive structure to simulate the strategy choices among different stakeholders. Therefore, it can be applied to understand principal-agent relationship and provide a comprehensive structure to simulate the interesting conflicts between enterprise owners and professional managers.

Therefore, based on the assumption of bounded rationality and asymmetric information, the authors take the 
conflicts of interests between the two parties of the game as the focus, introduce the principal-agent payoff into the game analysis process, and construct an asymmetric $2 \times 2$ dynamic evolutionary game model to find out the behavior evolution path of enterprise owners and professional managers. Through the dynamic evolutionary game analysis of the principal-agent relationship, the authors describe the behavioral decision-making and reaction strategies, analyze the rules of mutual restriction and interaction of both parties, and simulate the process of strategy choice based on a system dynamics model, which will increase the prediction accuracy better than traditional game models.

\section{Modeling}

There are two game stakeholders: enterprise owners and professional managers. In order to study their dynamic evolutionary game process and evolutionary stability strategies, the following assumptions are made:

(1) Bounded rationality: both enterprise owners and professional managers are economic individuals with bounded rationality, which means that they cannot make the optimal decision at the beginning. It requires constant trial and error and learning to find the optimal strategy. The principle for both parties to choose the optimal strategy is to maximize their respective interests according to their needs and circumstances.

(2) Asymmetric game: the enterprise owners and professional managers have different roles with different payoffs. There are two possible strategies for the enterprise owners: they can strengthen supervision to reduce the speculative behaviors of professional managers or let them run the company freely without any supervision. The strategy set can be described as $\{\mathrm{M}, \mathrm{NM}\}$ (M: Monitoring; NM: No monitoring). In response, professional managers also have two choices: make a great effort to manage the company or not to make a great effort to manage the company. The strategy set for enterprise owners can be described as $\{\mathrm{E}, \mathrm{NE}\}$ (E: Effort; NE: No effort). The strategy of enterprise owners and professional managers is shown in Table 1.

(3) The payoffs of the two parties in the game are directly related to the operation of the enterprise. For example, when professional managers choose the $\mathrm{E}$ strategy, regardless of whether the enterprise owners choose supervision or lack thereof, enterprise owners can obtain extra profit for the company's sound operation. On the contrary, when the professional managers choose the NE strategy and the enterprise owners choose the NM strategy, the owners will suffer losses for the speculative behavior of managers.

(4) Reputation effect of professional managers: when enterprise owners choose the M strategy, if professional managers choose the E strategy, they will gain reputation benefits in the managerial labor market. On the contrary, if professional managers choose the NE strategy, they will suffer a loss of reputation [40].

Based on these assumptions, the payoff matrix of enterprise owners and professional managers is shown in Table 2.

\section{Evolutionary Game Analysis}

3.1. Evolutionary Stability Strategy. When the enterprise owners and professional managers dynamically adjust their strategies during the game according to the payoffs of different strategies, it is necessary to construct an incomplete information evolutionary game model. If the possibility of the enterprise owners choosing the $\mathrm{M}$ strategy is $x(0<x<1)$, the possibility of choosing the NM strategy is $(1-x)$. If the possibility of professional managers choosing the E strategy is $y(0<y<1)$, the possibility of choosing the NE strategy is $(1-y)$. Based on the payoff matrix (Table 2), the payoffs from the two strategies for enterprise owners are $\mu_{1 m}$ and $\mu_{1 u}$, and the average payoff is $\overline{\mu_{1}}$ :

$$
\begin{aligned}
& \mu_{1 m}=y\left(R_{m}-C_{m}+T\right)+(1-y)\left(R_{m}-C_{m}\right), \\
& \mu_{1 u}=y\left(R_{u}+T\right)+(1-y)\left(R_{u}-S\right), \\
& \overline{\mu_{1}}=x \mu_{1 m}+(1-x) \mu_{1 u} .
\end{aligned}
$$

The replicated dynamic function $f(x)$ of the enterprise owner choosing the M strategy is obtained by combining equations (1) to (3):

$$
f(x)=\frac{\mathrm{d} x}{\mathrm{~d} t}=x\left(\mu_{1 m}-\overline{\mu_{1}}\right)=x(1-x)\left[y(-S)+R_{m}-C_{m}-R_{u}+S\right] .
$$

The first derivative of equation (4) with respect to $x$ is

$$
f^{\prime}(x)=(1-2 x)\left[y(-S)+R_{m}-C_{m}-R_{u}+S\right] .
$$

Let $f(x)=0$; there are three equilibrium points for the replication dynamic equation when enterprise owners choose the $\mathrm{M}$ strategy: $x_{1}=0, \quad x_{2}=1, \quad$ and $y=y^{*}=\left(R_{m}-C_{m}-R_{u}+S\right) / S:$

(1) If $y=y^{*}=\left(R_{m}-C_{m}-R_{u}+S\right) / S, f^{\prime}(x)=0$, so if professional managers choose the $\mathrm{E}$ strategy at the probability of $\left(R_{m}-C_{m}-R_{u}+S\right) / S$, there is no difference between the payoffs of the two strategies for enterprise owners; in other words, all $x$ is a stable state.

(2) If $y>y^{*}=\left(R_{m}-C_{m}-R_{u}+S\right) / S, f^{\prime}(0)<0$, and $f^{\prime}(1)>0$, then $x=0$ is an evolutionarily stable strategy. If professional managers choose the $\mathrm{E}$ strategy at the probability higher than $\left(R_{m}-C_{m}-R_{u}+S\right) / S$, enterprise owners will gradually change from the M strategy to the NM strategy, and then the NM strategy is the evolutionary stability strategy for enterprise owners. 
TABLE 1: The strategy of enterprise owners and professional managers.

\begin{tabular}{lccc}
\hline & & \multicolumn{2}{c}{ Professional managers } \\
& & Effort (E) & No effort (NE) \\
\hline \multirow{2}{*}{ Enterprise owners } & Monitoring (M) & (Monitoring, effort) & (Monitoring, no effort) \\
& No monitoring (NM) & (No monitoring, effort) & (No monitoring, no effort) \\
\hline
\end{tabular}

TABLE 2: Payoff matrix of enterprise owners and professional managers.

\begin{tabular}{lccc}
\hline & & \multicolumn{2}{c}{ Professional managers } \\
& & Effort $(\mathrm{E})$ & No effort $(\mathrm{NE})$ \\
\hline Enterprise owners & Monitoring $(\mathrm{M})$ & $\left(R_{m}-C_{m}+T, R_{d}-C_{d}+F\right)$ & $\left(R_{m}-C_{m}, R_{i}-F\right)$ \\
& No monitoring (NM) & $\left(R_{u}+T, R_{d}-C_{d}\right)$ & $\left(R_{u}-S, R_{i}\right)$ \\
\hline
\end{tabular}

$R_{m}$ is the income of enterprise owners when they choose the $\mathrm{M}$ strategy, which refers to the higher income due the supervision to managers and active participation of company governance, $R_{m} \in(0,+\infty) ; R_{u}$ is the income of enterprise owners when they choose the NM strategy, which refers to the lower income due to the lack of supervision to managers and participation of company governance, $R_{u} \in\left(0, R_{m}\right) C_{m}$ is the cost of enterprise owners for monitoring the professional managers, $C_{m} \in\left(0, R_{m}\right) ; T$ is the income of enterprise owners because the professional managers make a great effort to manage the company, $T \in(0,+\infty) ; R_{d}$ is the income of professional managers when they choose the $\mathrm{E}$ strategy, which refers to the higher income due to their great efforts to manage the company, $R_{d} \in(0,+\infty) ; R_{i}$ is the income of professional managers when they choose the NE strategy, which refers to the lower income due to their lack of efforts to manage the company, $R_{i} \in\left(0, R_{d}\right)$; $C_{d}$ is the cost of professional managers for making a great effort to manage the company, $C_{d} \in\left(0, R_{d}\right) ; F$ is the gain of professional managers, which is the reputation gain when the strategy choices are $\{\mathrm{M}, \mathrm{E}\}$ and the loss of reputation when the strategy choices are $\{\mathrm{M}, \mathrm{NE}\}, F \in(0,+\infty)$; $S$ is the loss of professional managers, which is the profit loss suffered by the enterprise owners when the strategy choices are $\{\mathrm{NM}, \mathrm{NE}\}, S \in(0,+\infty)$.

(3) If $y<y^{*}=\left(R_{m}-C_{m}-R_{u}+S\right) / S, f^{\prime}(1)<0$, and $f^{\prime}(0)>0$, then $x=1$ is an evolutionarily stable strategy. If professional managers choose the $\mathrm{E}$ strategy at the probability lower than $\left(R_{m}-C_{m}-R_{u}+S\right) / S$, enterprise owners will gradually change from the NM strategy to the M strategy, and then the M strategy is the evolutionary stability strategy for enterprise owners.

The dynamic evolution path of the enterprise owner is shown in Figure 1.

As above, the payoffs from the two strategies for professional managers are $\mu_{2 d}$ and $\mu_{2 i}$, and the average payoff is $\overline{\mu_{2}}$ :

$$
\begin{aligned}
\mu_{2 d} & =x\left(R_{d}-C_{d}+F\right)+(1-x)\left(R_{d}-C_{d}\right), \\
\mu_{2 i} & =x\left(R_{i}-F\right)+(1-x) R_{i}, \\
\overline{\mu_{2}} & =y \mu_{2 d}+(1-y) \mu_{2 i} .
\end{aligned}
$$

The replicated dynamic function $f(y)$ of professional manager choosing the $\mathrm{E}$ strategy is obtained by combining equations (6) to (8):

$$
f(y)=\frac{\mathrm{d} y}{\mathrm{~d} t}=y\left(\mu_{2 d}-\overline{\mu_{2}}\right)=y(1-y)\left(2 F x+R_{d}-C_{d}-R_{i}\right) .
$$

The first derivative of equation (9) with respect to $y$ is

$$
f^{\prime}(y)=(1-2 y)\left(2 F x+R_{d}-C_{d}-R_{i}\right) .
$$

Let $f(y)=0$; there are three equilibrium points for the replication dynamic equation when professional managers choose the $\mathrm{E}$ strategy: $y_{1}=0, \quad y_{2}=1, \quad$ and $x=x^{*}=-\left(R_{d}-C_{d}-R_{i}\right) / 2 F$.

The same method is used to analyze the stable evolution strategy of professional managers. Under the different scenarios: $\quad x=x^{*}=-\left(R_{d}-C_{d}-R_{i}\right) / 2 F, \quad x<x^{*}=-$ $\left(R_{d}-C_{d}-R_{i}\right) / 2 F$, and $x>x^{*}=-\left(R_{d}-C_{d}-R_{i}\right) / 2 F$, the dynamic evolution paths of the professional manager are shown in Figure 2.

In summary, replication of the dynamic relationship between enterprise owners and professional managers is shown in Figure 3.

3.2. System Stability Analysis. The two replicated dynamic functions $f(x)$ and $f(y)$ constitute the dynamic replication system of the principal-agent evolutionary game. There are five partial equilibrium points: $\mathrm{A}(0,0), \mathrm{B}(0,1), \mathrm{C}(1,0)$, $\mathrm{D}(1,1)$, and $\mathrm{E}-\left(R_{d}-C_{d}-R_{i}\right) / 2 F,\left(R_{m}-C_{m}-R_{u}+S\right) / S$. These are the equilibrium states of the evolutionary game, representing the evolutionarily stable strategy for both parties. The points can be obtained by partial equilibrium analysis of the determinant and trace of the Jacobian matrix [41]. The Jacobian matrix of the principal-agent evolutionary game is 


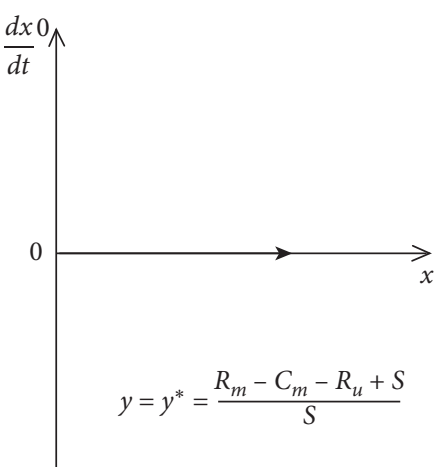

(a)

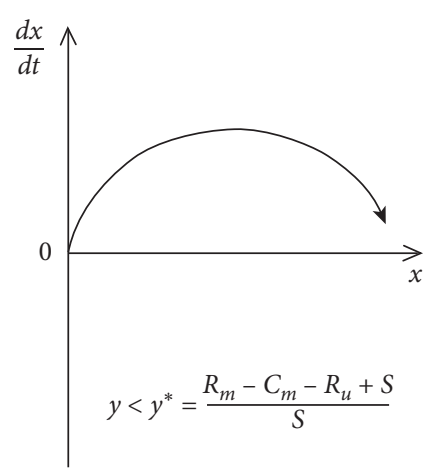

(b)

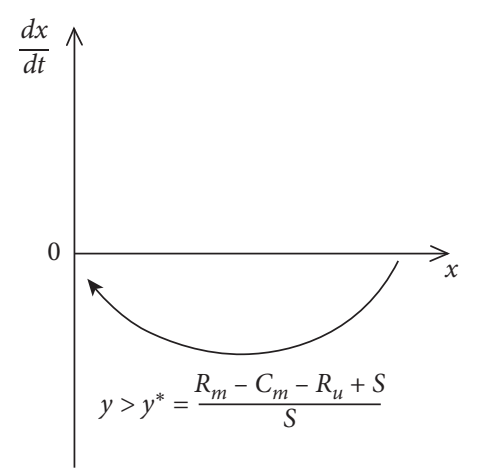

(c)

FIgURE 1: Dynamic evolution path of the enterprise owners.

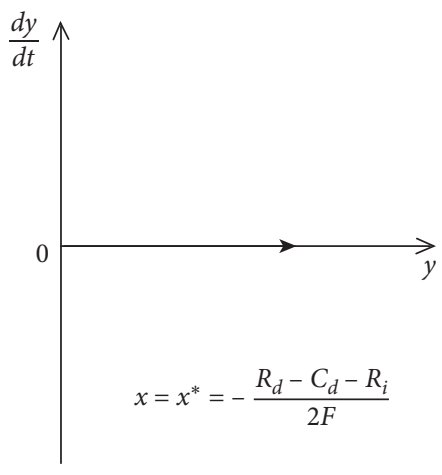

(a)

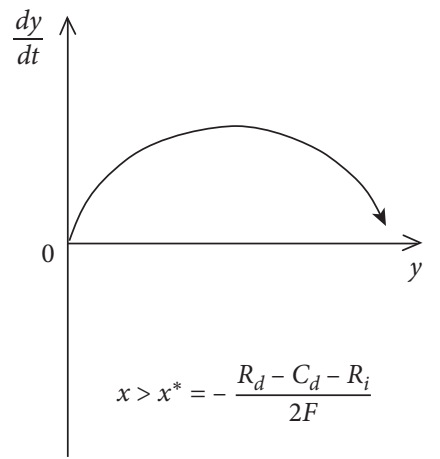

(b)

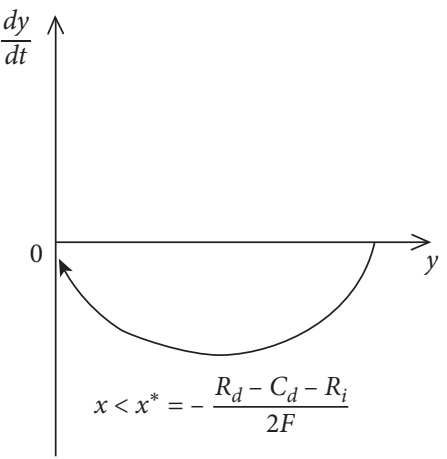

(c)

FIGURE 2: Dynamic evolution path of professional managers.

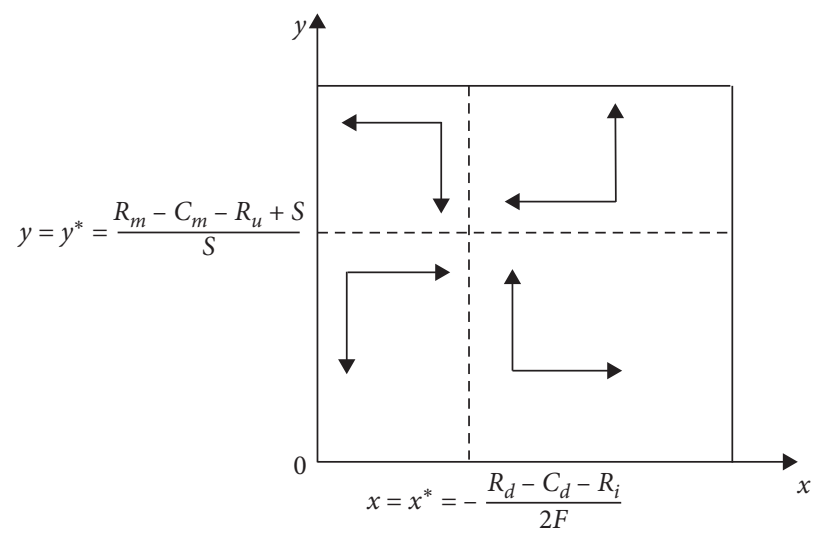

FIgURE 3: The evolution game of enterprise owners and professional managers.

$$
J=\left[\begin{array}{ll}
\frac{\partial f(x)}{\partial x} & \frac{\partial f(x)}{\partial y} \\
\frac{\partial f(y)}{\partial x} & \frac{\partial f(y)}{\partial y}
\end{array}\right]=\left[\begin{array}{cc}
(1-2 x)\left[y(-S)+R_{m}-C_{m}-R_{u}+S\right] & x(1-x)(-S) \\
2 F y(1-y) & (1-2 y)\left(2 F x+R_{d}-C_{d}-R_{i}\right)
\end{array}\right]
$$

Thus, the determinant Det $(J)$ and trace $\operatorname{Tr}(J)$ of Jacobian matrix are 


$$
\begin{aligned}
\operatorname{Det}(J) & =\frac{\partial f(x)}{\partial x} \frac{\partial f(y)}{\partial y}-\frac{\partial f(x)}{\partial y} \frac{\partial f(y)}{\partial x} \\
\operatorname{Tr}(J) & =\frac{\partial f(x)}{\partial x}+\frac{\partial f(y)}{\partial y} \\
\operatorname{Det}(J) & =(1-2 x)(1-2 y)\left[y(-S)+R_{m}-C_{m}-R_{u}+S\right]\left(2 F x+R_{d}-C_{d}-R_{i}\right)-2 F(-S) x y(1-x)(1-y) \\
\operatorname{Tr}(J) & =(1-2 x)\left[y(-S)+R_{m}-C_{m}-R_{u}+S\right]+(1-2 y)\left(2 F x+R_{d}-C_{d}-R_{i}\right)
\end{aligned}
$$

If $\operatorname{Det}(J)>0$ and $\operatorname{Tr}(J)<0$, the equilibrium points represent the evolutionarily stable strategy for both parties [42-44], and the determinant and trace of the five equilibrium points $\mathrm{A}, \mathrm{B}, \mathrm{C}, \mathrm{D}$, and $\mathrm{E}$ are as given in Table 3 .

In order to simplify the parameter discussion process, assume that $V_{1}=R_{m}-C_{m}-R_{u}$, which means the difference between the net income of the $\mathrm{M}$ strategy $\left(R_{m}-C_{m}\right)$ and the income of the NM strategy $R_{u}$ for enterprise owners. $V_{2}=R_{m}-C_{m}-R_{u}+S$, which means if the goal of professional managers is inconsistent with the goal of the company, then considering the loss $S$ suffered, the difference between the net income of the $\mathrm{M}$ strategy $\left(R_{m}-C_{m}\right)$ and the income of the NM strategy $R_{u}$ for enterprise owners, thus $V_{2}=V_{1}+S . V_{3}=R_{d}-C_{d}-R_{i}$, which means the difference between the net income of the E strategy $\left(R_{d}-C_{d}\right)$ and the income of the NE strategy $R_{i}$ for professional managers. $V_{4}=2 F+R_{d}-C_{d}-R_{i}$, which is under the promise of the sound managerial labor market; then considering the effect of gain and loss of reputation, the difference between the net income of the E strategy $\left(R_{d}-C_{d}\right)$ and the income of the NE strategy $R_{i}$ for professional managers, thus $V_{4}=V_{3}+2 F$. The Jacobian matrix could be abbreviated as Table 4 .

According to Table 4, the variables of $V_{1}, V_{2}, V_{3}, V_{4}$ are the key determining parameters of the evolutionary stability strategies; there are 18 different scenarios as given in Table 5.

Under the following scenarios: (1) $V_{1}>0, V_{2}$ $>0, V_{3}>0, V_{4}>0$ and (2) $V_{1}>0, V_{2}>0, V_{3}<0, V_{4}>0$, the evolutionary stability point is $\mathrm{D}(1,1)$ and the evolutionary stable strategy is $\{\mathrm{M}, \mathrm{E}\}$ as shown in Figure 4. For enterprise owners, the net income of the $\mathrm{M}$ strategy $\left(R_{m}-C_{m}\right)$ is greater than the income of the NM strategy $R_{u}$. For professional managers, the net income of the E strategy $\left(R_{d}-\right.$ $C_{d}$ ) is greater than the income of the NE strategy $R_{i}$. As a rational stakeholder, they will continue to choose the $M$ strategy and the E strategy as their dominant strategies. The stable states of partial equilibrium points for scenarios (1) and (2) are shown in Supplementary Materials Table A1.

Under the following scenarios: (6) $V_{1}<0, V_{2}$ $>0, V_{3}>0, V_{4}>0, V_{1}>V_{4},(7) V_{1}<0, V_{2}>0, V_{3}>0, V_{4}>0$, $V_{1}<V_{4}$, (12) $V_{1}<0, V_{2}<0, V_{3}>0, V_{4}>0, V_{2}>V_{4}, V_{1}>V_{4}$, and (13) $V_{1}<0, V_{2}<0, V_{3}>0, V_{4}>0, V_{2}>V_{4}, V_{1}<V_{4}$, the evolutionary stable point is point $\mathrm{B}(0,1)$ and the evolutionary stable strategy is $\{\mathrm{NM}, \mathrm{E}\}$ as shown in Figure 5. Take scenario (6) as an example: for enterprise owners, as the net income of the M strategy $\left(R_{m}-C_{m}\right)$ is less than the income of the NM strategy $R_{u}$, they tend to choose the NM strategy even though they may suffer profit loss $S$. For professional managers, as the net income of the E strategy $\left(R_{d}-C_{d}\right)$ is greater than the income of the NE strategy $R_{i}$, they will also choose the E strategy even if the owners choose the NM strategy. The stable states of partial equilibrium points for scenario (6), (7), (12), and (13) are shown in Supplementary Materials Table A2.

Under the following scenarios: (3) $V_{1}>0, V_{2}>0, V_{3}<0$, $V_{4}<0, V_{2}>V_{4}, V_{1}>V_{4}$, (4) $V_{1}>0, V_{2}>0, V_{3}<0, V_{4}$ $<0, V_{2}>V_{4}, V_{1}<V_{4}$, and (10) $V_{1}<0, V_{2}>0, V_{3}<0$, $V_{4}<0, V_{2}>V_{4}$, the stable point is point $\mathrm{C}(1,0)$ and the evolutionary stable strategy is $\{\mathrm{M}, \mathrm{NE}\}$ as shown in Figure 6. Take scenario (3) as an example: for enterprise owners, as the net income of the M strategy $\left(R_{m}-C_{m}\right)$ is greater than the income of the NM strategy $R_{u}$, they tend to choose the $\mathrm{M}$ strategy in order to maximize their income and avoid loss $S$. For professional managers, as the net income of the $\mathrm{E}$ strategy $\left(R_{d}-C_{d}\right)$ is greater than the income of the $\mathrm{NE}$ strategy $R_{i}$ and the reputation gain of the E strategy $F$ is less than the income of the E strategy $R_{i}$, professional managers tend to choose the NE strategy to maximize the income even at the risk of losing the reputation $F$. The stable states of partial equilibrium points for scenarios (3) and (4) are shown in Supplementary Materials Table A3.

Under the scenario (18) $V_{1}<0, V_{2}<0, V_{3}<0, V_{4}<0$, the stable point is $A(0,0)$ and the evolutionary stable strategy is $\{\mathrm{NM}, \mathrm{NE}\}$ as shown in Figure 7. For enterprise owners, the net income of the $\mathrm{M}$ strategy $\left(R_{m}-C_{m}\right)$ is less than the income of the NM strategy $R_{u}$ and the profit loss $S$ of the M strategy does not exceed the acceptable range of the owner, so enterprise owners will take the NM strategy as the dominant strategy. For professional managers, the net income of the E strategy $\left(R_{d}-C_{d}\right)$ is less than the income of the NE strategy $R_{i}$, and the reputation gain $F$ is less than the income of the E strategy $R_{i}$. The incentive policy of enterprises is invalid, and professional managers as rational stakeholders will be more inclined to choose the NE strategy. The stable states of partial equilibrium points for scenario (18) are shown in Supplementary Materials Table A4.

Under the scenario (14) $V_{1}<0, V_{2}<0$, $V_{3}>0, V_{4}>0, V_{2}<V_{4}, V_{1}<V_{4}$, there are two stable points: $\mathrm{B}(0,1)$ and $\mathrm{C}(1,0)$. The evolutionary stable strategies are $\{\mathrm{NM}, \mathrm{E}\}$ and $\{\mathrm{M}, \mathrm{NE}\}$ as shown in Figure 8. For enterprise owners, as the net income of the M strategy $\left(R_{m}-C_{m}\right)$ is less than the income of the NM strategy $R_{u}$, they will take the $\mathrm{NM}$ strategy as their dominant strategy. For professional managers, the net income of the E strategy $\left(R_{d}-C_{d}\right)$ and the reputation gain $F$ are higher than the income of the $\mathrm{NE}$ 
TABLE 3: Determinant and trace of partial equilibrium points.

\begin{tabular}{lcc}
\hline & $\operatorname{Det}(J)$ & $\operatorname{Tr}(J)$ \\
\hline $\mathrm{A}(0,0)$ & $\left(R_{m}-C_{m}-R_{u}+S\right)\left(R_{d}-C_{d}-R_{i}\right)$ & $\left(R_{m}-C_{m}-R_{u}+S\right)+\left(R_{d}-C_{d}-R_{i}\right)$ \\
$\mathrm{B}(0,1)$ & $-\left(R_{m}-C_{m}-R_{u}\right)\left(R_{d}-C_{d}-R_{i}\right)$ & $\left(R_{m}-C_{m}-R_{u}\right)-\left(R_{d}-C_{d}-R_{i}\right)$ \\
$\mathrm{C}(1,0)$ & $-\left(R_{m}-C_{m}-R_{u}+S\right)\left(2 F+R_{d}-C_{d}-R_{i}\right)$ & $-\left(R_{m}-C_{m}-R_{u}+S\right)-\left(2 F+R_{d}-C_{d}-R_{i}\right)$ \\
$\mathrm{D}(1,1)$ & $\left(R_{m}-C_{m}-R_{u}\right)\left(2 F+R_{d}-C_{d}-R_{i}\right)$ & $-\left(R_{m}-C_{m}-R_{u}\right)-\left(2 F+R_{d}-C_{d}-R_{i}\right)$ \\
$E\left(x^{*}, y^{*}\right)$ & $\left(\left(R_{m}-C_{m}-R_{u}\right)\left(R_{m}-C_{m}-R_{u}+S\right)\left(2 F+R_{d}-C_{d}-R_{i}\right)\left(R_{d}-C_{d}-R_{i}\right) / 2 F S\right)$ & 0 \\
\hline
\end{tabular}

TABle 4: The simplified determinant and trace of partial equilibrium points.

\begin{tabular}{lcc}
\hline & Det $(J)$ & $\operatorname{Tr}(J)$ \\
\hline A $(0,0)$ & $V_{2} V_{3}$ & $V_{2}+V_{3}$ \\
B $(0,1)$ & $-V_{1} V_{3}$ & $V_{1}-V_{3}$ \\
C $(1,0)$ & $-V_{2} V_{4}$ & $-V_{2}-V_{4}$ \\
D $(1,1)$ & $V_{1} V_{4}$ & $-V_{1}-V_{4}$ \\
E $\left(x^{*}, y^{*}\right)$ & $V_{1} V_{2} V_{3} V_{4} / 2 F S$ & 0 \\
\hline
\end{tabular}

TABLE 5: Summary of different scenarios.
(1) $V_{1}>0, V_{2}>0, V_{3}>0, V_{4}>0$
(2) $V_{1}>0, V_{2}>0, V_{3}<0, V_{4}>0$
(3) $V_{1}>0, V_{2}>0, V_{3}<0, V_{4}<0, V_{2}>V_{4}, V_{1}>V_{4}$
(4) $V_{1}>0, V_{2}>0, V_{3}<0, V_{4}<0, V_{2}>V_{4}, V_{1}<V_{4}$
(5) $V_{1}>0, V_{2}>0, V_{3}<0, V_{4}<0, V_{2}<V_{4}, V_{1}<V_{4}$
(6) $V_{1}<0, V_{2}>0, V_{3}>0, V_{4}>0, V_{1}>V_{4}$
(7) $V_{1}<0, V_{2}>0, V_{3}>0, V_{4}>0, V_{1}<V_{4}$
(8) $V_{1}<0, V_{2}>0, V_{3}<0, V_{4}>0, V_{1}>V_{4}$
(9) $V_{1}<0, V_{2}>0, V_{3}<0, V_{4}<0, V_{2}<V_{4}$
(10) $V_{1}<0, V_{2}>0, V_{3}<0, V_{4}<0, V_{2}>V_{4}$
(11) $V_{1}<0, V_{2}>0, V_{3}<0, V_{4}<0, V_{2}<V_{4}$
(12) $V_{1}<0, V_{2}<0, V_{3}>0, V_{4}>0, V_{2}>V_{4}, V_{1}>V_{4}$
(13) $V_{1}<0, V_{2}<0, V_{3}>0, V_{4}>0, V_{2}>V_{4}, V_{1}<V_{4}$
(14) $V_{1}<0, V_{2}<0, V_{3}>0, V_{4}>0, V_{2}<V_{4}, V_{1}<V_{4}$
(15) $V_{1}<0, V_{2}<0, V_{3}<0, V_{4}>0, V_{2}>V_{4}, V_{1}>V_{4}$
(16) $V_{1}<0, V_{2}<0, V_{3}<0, V_{4}>0, V_{2}>V_{4}, V_{1}<V_{4}$
(17) $V_{1}<0, V_{2}<0, V_{3}<0, V_{4}>0, V_{2}<V_{4}, V_{1}<V_{4}$
(18) $V_{1}<0, V_{2}<0, V_{3}<0, V_{4}<0$

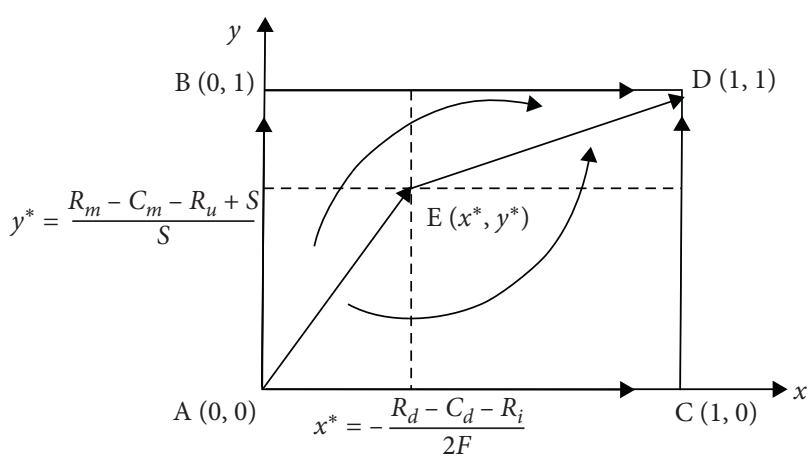

FIgURE 4: The replication dynamic phase map for scenarios (1) and (2).

strategy $R_{i}$; therefore professional managers choose the $\mathrm{E}$ strategy. However, with the increase of the possibility of professional managers choosing the E strategy, enterprise owners may turn to the NM strategy in order to avoid costs of supervising $C_{m}$ and obtain extra profit $T$. At this time, due

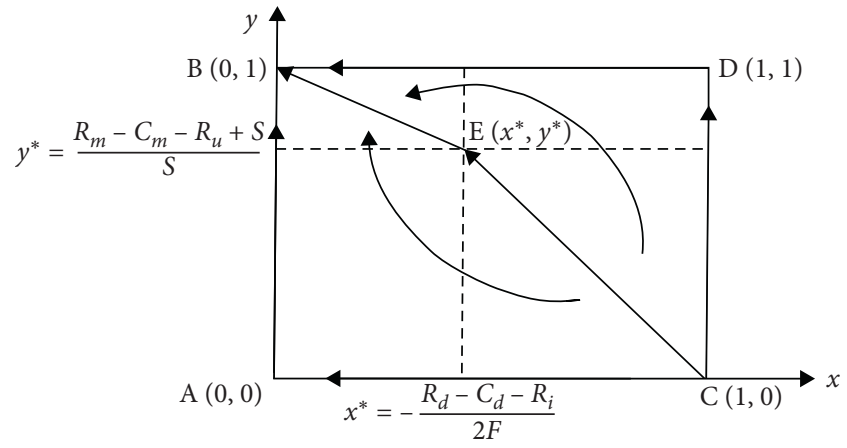

FIgURE 5: The replication dynamic phase map for scenarios (6), (7), (12), and (13).

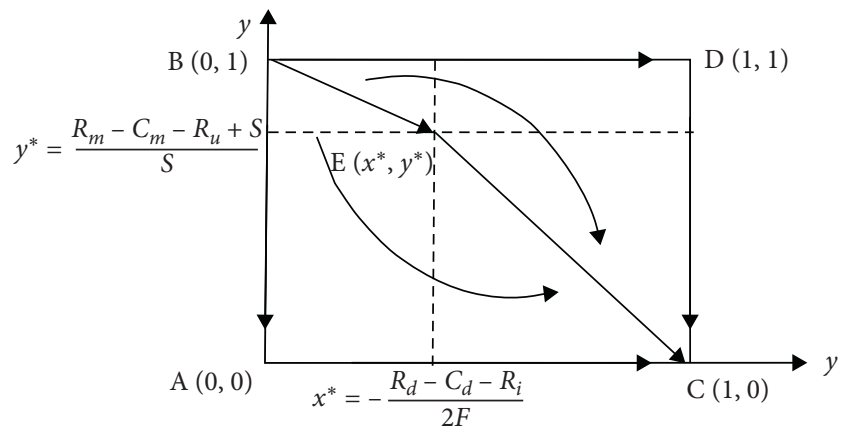

Figure 6: The replication dynamic phase map for scenarios (3) and (4).

to the owner's nonsupervised behavior, the decrease of reputation gain $F$ and the increase of effort cost $C_{d}$ cause professional managers to change their strategies. The possibility of professional managers choosing the E strategy is closer from 1 to 0 . Finally, the two sides achieve evolutionary stability at points $\mathrm{B}(0,1)$ and $\mathrm{C}(1,0)$. The stable states of partial equilibrium points for scenario (14) are shown in Supplementary Material Table A5. 


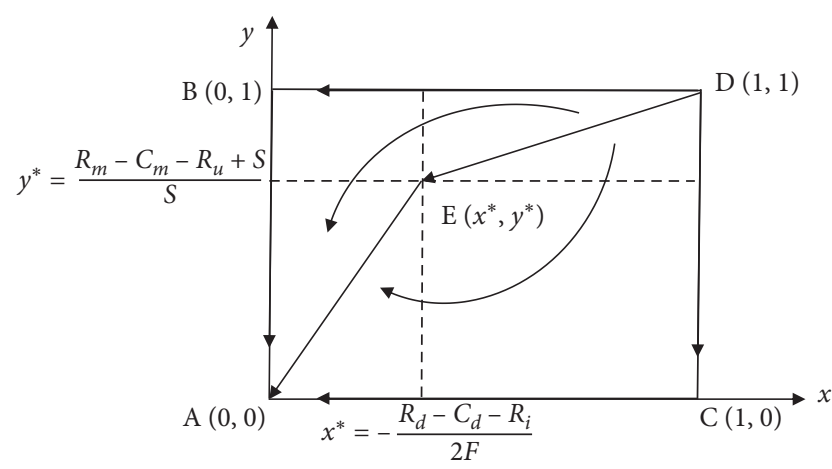

Figure 7: The replication dynamic phase map for scenario (18).

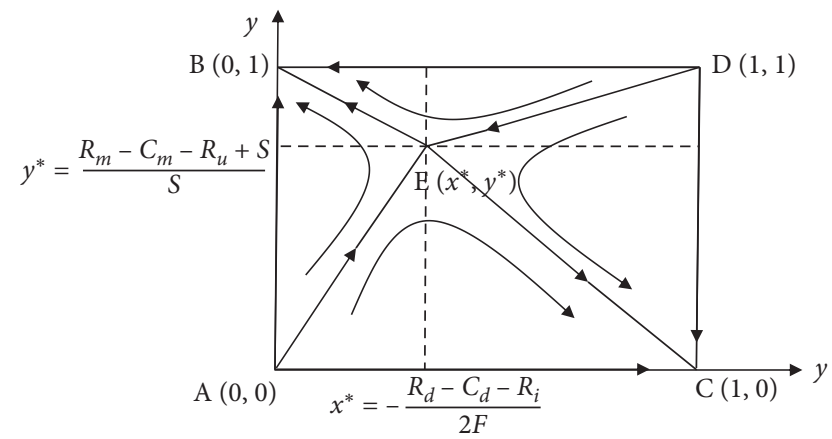

FIGURE 8: The replication dynamic phase map for scenario (14).

Under the scenario (17) $V_{1}<0, V_{2}<0, V_{3}<0, V_{4}>0$, $V_{2}<V_{4}, V_{1}<V_{4}$, there are also two stable points: A $(0,0)$ and $C(1,0)$ and the evolutionary stable strategies are $\{\mathrm{NM}$, $\mathrm{NE}\}$ and $\{\mathrm{M}, \mathrm{NE}\}$ as shown in Figure 9. For professional managers, the net income of the E strategy $\left(R_{d}-C_{d}\right)$ is less than the income of the NE strategy $R_{i}$, so professional managers are more inclined to choose the NE strategy. For the enterprise owners, as the net income of the M strategy $\left(R_{m}-C_{m}\right)$ is less than the income of the NM strategy $R_{u}$, the enterprise owners will choose the NM strategy at the beginning. However, with the increasing probability that professional managers choose the NE strategy, enterprise owners may turn to the M strategy to avoid profit loss $S$. Since the net income of the NE strategy $\left(R_{d}-C_{d}\right)$ is always higher than that of the E strategy $R_{i}$, the strategy change of enterprise owners will not change the professional managers' strategic choices. Finally, both parties achieve evolutionary stability at points $\mathrm{A}(0,0)$ and $\mathrm{C}(1,0)$. The stable states of partial equilibrium points for scenario (17) are shown in Supplementary Material Table A6.

Under the following scenarios: (5) $V_{1}>0, V_{2}>0, V$ $3<0, V_{4}<0, V_{2}>V_{4}, V_{1}<V_{4}$, (8) $V_{1}<0, V_{2}>0, V_{3}<0, V_{4}$ $>0, V_{1}>V_{4}$, (9) $V_{1}<0, V_{2}>0, V_{3}<0, V_{4}<0, V_{2}<V_{4}$, (11) $V_{1}<0, V_{2}>0, V_{3} \quad<0, V_{4}<0, V_{2}<V_{4}, \quad(15) \quad V_{1}<0$, $V_{2}<0, V_{3}<0, V_{4}>0, V_{2}>V_{4}, V_{1}>V_{4}$, and (16) $V_{1}$ $<0, V_{2}<0, V_{3}<0, V_{4}>0, V_{2}>V_{4}, V_{1}<V_{4}$, there is no evolutionary stable strategy. The long-term evolution of the principal-agent cannot find the evolution equilibrium point, and at this time the strategies of both sides of the game are constantly changing. For enterprise owners and professional

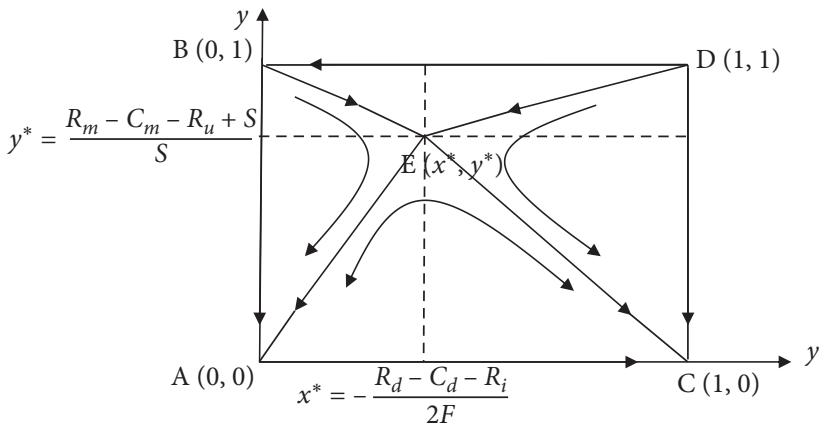

Figure 9: The replication dynamic phase map for scenario (17).

managers, the net income of choosing the $\mathrm{M}$ strategy or the $\mathrm{E}$ strategy is greater than that of the NM strategy or the NE strategy. However, due to the existence of reputation gain and loss $F$ and profit loss $S$, both parties are not convinced their strategy is the optimal strategy and therefore expect to make adjustments according to the other party's possible strategy as shown in Figure 10. The stable states of partial equilibrium points for scenarios (5), (8), (9), (11), (15), and (16) are shown in Supplementary Material Table A7.

In summary, the evolutionary stable strategies of 18 different scenarios are as given in Table 6.

3.3. Simulation Results. The evolution path of the game is determined by different utility parameters, so it is necessary to verify the results of the game model through dynamic evolutionary simulation [45]. To assess the impact of different factors on the evolution of the strategic choices of the enterprise owners and professional managers, a system dynamics model for the principal-agent was constructed in Vensim PLS. The simulation model is comprised of two main subsystems capable of simulating the strategy choice of enterprise owners and professional managers based on the evolutionary stability strategy analysis. The model consists of 4 level variables, 2 flow variables, 9 external variables, and 16 intermediate variables as shown in Figure 11. The 4 level variables represent the probability that enterprise owners choose the M strategy or NM strategy and the probability that professional managers choose the E or NE strategy. The 2 flow variables represent the change rate of enterprise owners choosing M strategy to NM strategy and the change rate of professional managers choosing NE strategy to $\mathrm{E}$ strategy. The 9 external variables correspond to the variables in the payoff matrix as shown in Table 1 . The 16 intermediate variables are the payoff and expected payoff of enterprise owners and professional managers choosing different strategies and the difference in the expected payoff. The arrow represents the relationship between different variables.

The time limit of the model is set as follows: INITIAL TIME $=0$, FINAL TIME $=20$, TIME STEP $=1$. Due to it is hard to find a real case for system dynamics simulation, it is better to analyze the system evolution characteristics of the evolutionary game through simulation. Firstly, determine the size relationship between the data according to the 


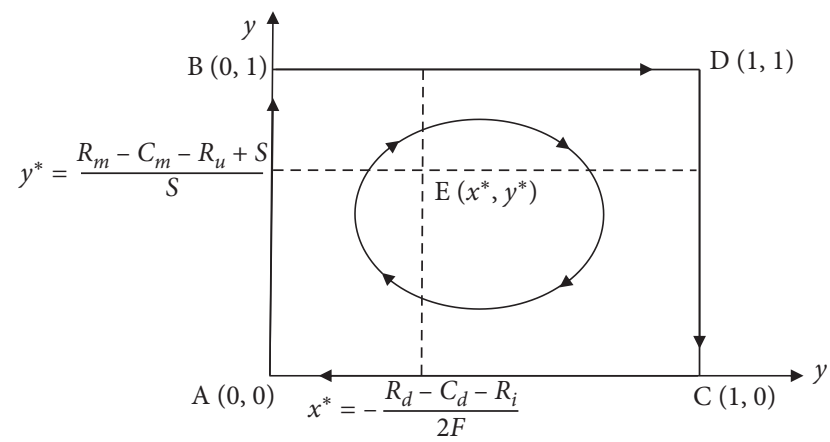

Figure 10: The replication dynamic phase map for scenarios (5), (8), (9), (11), (15), and (16).

TABLE 6: Summary of the evolutionary stable strategies of 18 scenarios.

\begin{tabular}{lc}
\hline Scenarios & Evolutionary stable strategies \\
\hline$(1)(2)$ & $\{\mathrm{M}, \mathrm{E}\}$ \\
$(3)(4)(10)$ & $\{\mathrm{M}, \mathrm{NE}\}$ \\
$(6)(7)(12)(13)$ & $\{\mathrm{NM}, \mathrm{E}\}$ \\
$(18)$ & $\{\mathrm{NM}, \mathrm{E}\},\{\mathrm{M}, \mathrm{NE}\}$ \\
$(14)$ & $\{\mathrm{NM}, \mathrm{NE}\},\{\mathrm{M}, \mathrm{NE}\}$ \\
$(17)$ & $\mathrm{No} \mathrm{ESS}$ \\
\hline
\end{tabular}

assumptions. Secondly, in order to ensure the logic of the parameters and the simplicity of analysis, the value range of the data is determined. Finally, the value is randomly assigned within the value range. The meanings and initial values of each external variable are shown in Table 7.

It was assumed that only one variable changes while the others remain constant in the simulation. The simulation results are as follows.

(1) The impact of $R_{m}$ on the evolutionary results:

When $R_{m}$ is increasing and the probability of the enterprise owner choosing the $M$ strategy is increasing, the difference between the expected payoffs of professional managers choosing the E strategy and NE strategy $\left(\mu_{2 d}-\mu_{2 i}\right)$ was reduced, resulting in professional managers' hesitation in the process of strategic choices and the probability of choosing the E strategy is decreasing. However, because the expected payoff of the E strategy is still greater than that of the NE strategy, professional managers will eventually choose the E strategy.

When $R_{m}$ gradually decreases from the initial value 1.5 to 1.2 , the difference between the expected payoffs of choosing the M strategy and NM strategy $\left(\mu_{1 m}-\mu_{1 u}\right)$ decreases, so the probability of the enterprise owners choosing the $\mathrm{M}$ strategy decreases as shown in Figure 12. When $R_{m}$ decreases to 1.2, the probability of the enterprise owners choosing the $\mathrm{M}$ strategy decreases, and owners will choose the NM strategy; then the evolutionary equilibrium point is $\{\mathrm{NM}, \mathrm{E}\}$. When $R_{m}$ gradually increases from the initial value of 1.5 to 1.8 , the probability of enterprise owners choosing the $\mathrm{M}$ strategy will continue to increase and the evolutionary equilibrium point is $\{\mathrm{M}, \mathrm{E}\}$.

(2) The impact of $R_{u}$ on the evolutionary results:

When $R_{u}$ increases and the probability of the enterprise owner choosing the M strategy decreases gradually, the difference between the expected payoffs of choosing the E and NE strategy increases; then the probability of professional managers choosing the E strategy will increase unceasingly and finally they will choose the E strategy as shown in Figure 13 . When $R_{u}$ gradually reduced from the initial value of 1.0 to 0.7 , the probability of the owner choosing the M strategy is increasing, and eventually they choose the $\mathrm{M}$ strategy and the evolutionary equilibrium point is $\{\mathrm{M}, \mathrm{E}\}$. When $R_{u}$ gradually increases to 1.3 and the probability of enterprise owners choosing the M strategy decreases, they finally choose the NM strategy, so the evolutionary equilibrium point is $\{\mathrm{NM}, \mathrm{E}\}$.

(3) The impact of $C_{m}$ on the evolutionary results:

When $C_{m}$ is increasing and the probability of enterprise owners choosing $\mathrm{M}$ is decreasing, which increases the difference between the expected payoffs of the E strategy and NE strategy, the probability of professional managers choosing the E strategy increases with the number of times of simulation as shown in Figure 14.

When $C_{m}$ gradually decreases from the initial value of 0.4 to 0.1 , the probability of enterprise owners choosing the $\mathrm{M}$ strategy is increasing and eventually they choose the M strategy. Then the evolutionary equilibrium point is $\{\mathrm{M}, \mathrm{E}\}$. When $C_{m}$ increases gradually to 0.7 , the probability of enterprise owners choosing the M strategy decreases and finally they choose the NM strategy. The evolutionary equilibrium point is $\{\mathrm{NM}, \mathrm{E}\}$.

(4) The impact of $T$ on the evolutionary results:

If the professional manager chooses the E strategy, the $T$ will not affect the expected payoffs of the enterprise owners of choosing the M strategy and NM strategy in the simulation model as shown in Figure 15. If the professional manager chooses the $\mathrm{E}$ strategy, regardless of the enterprise owners choosing either the M strategy or NM strategy, the enterprise owners can obtain extra profit due to the increase in value. On the contrary, enterprise owners cannot obtain extra profit $T$ if the professional managers choose the NE strategy, so the strategic choices of enterprise owners remain unchanged and the evolutionary equilibrium point is $\{\mathrm{M}, \mathrm{E}\}$.

(5) The impact of $S$ on the evolutionary results:

With $S$ increasing, then the enterprise owners are more inclined to choose the M strategy to avoid profit loss. Professional managers will choose the E strategy if expected enterprise owners choose the $M$ 


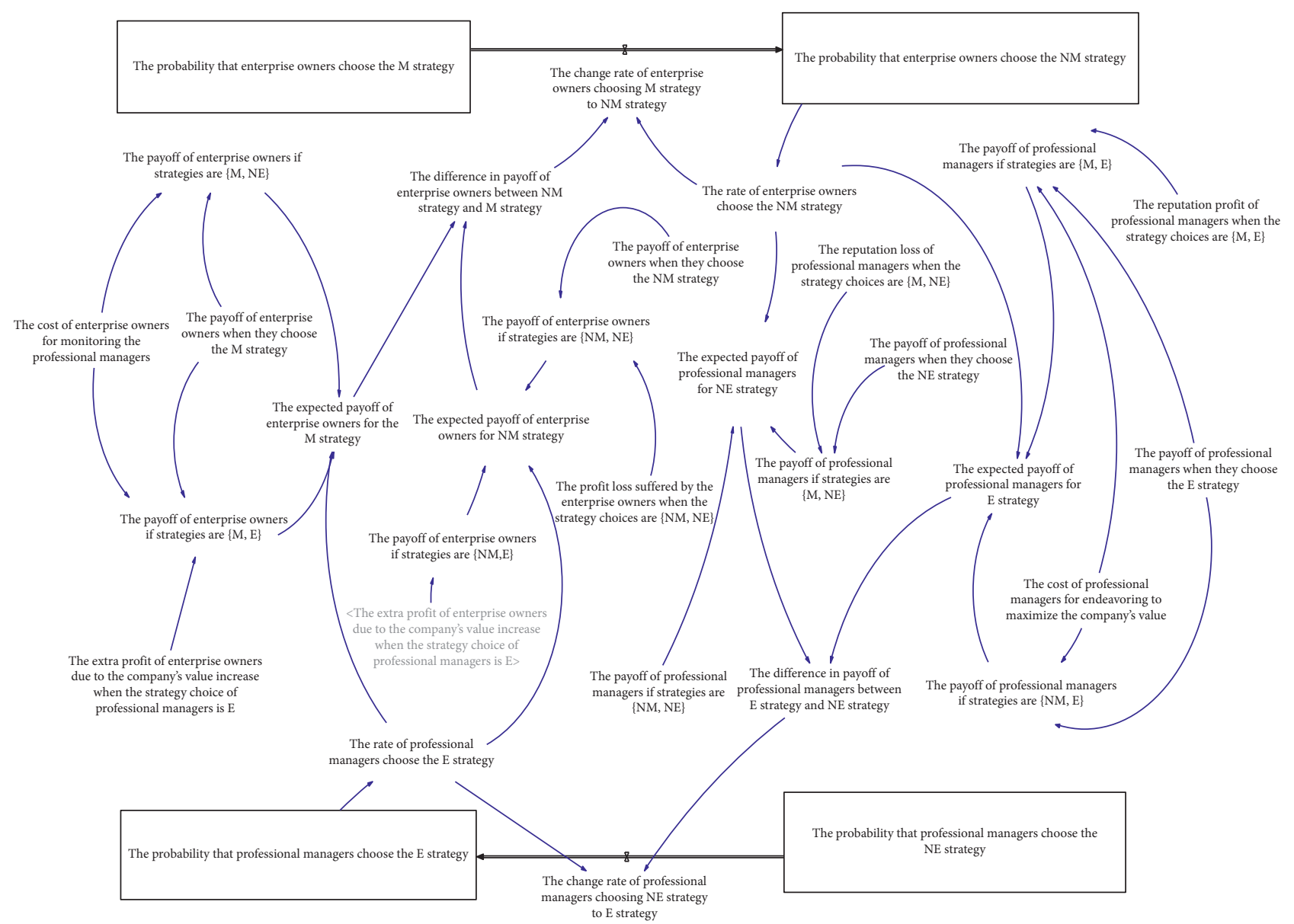

FIGURE 11: System dynamics model of principal-agent problem.

TABLE 7: The external variables and initial values of the system dynamics model.

\begin{tabular}{|c|c|c|}
\hline Variables & Definitions & Initial value \\
\hline$R_{m}$ & The income of the enterprise owner when choosing the M strategy & 1.5 \\
\hline$R_{u}^{m}$ & The income of the enterprise owners when choosing the NM strategy & 1.0 \\
\hline$C_{m}$ & The cost of enterprise owners for monitoring the professional managers & 0.4 \\
\hline$T$ & $\begin{array}{c}\text { The income of enterprise owners when professional managers make a great effort to manage the company when } \\
\text { the strategy choices are }\{M, E\} \text { or }\{N M, E\}\end{array}$ & 0.3 \\
\hline$S$ & The loss of enterprise owners when the strategy choices are $\{N M, N E\}$ & 0.2 \\
\hline$R_{d}$ & The income of professional managers when choosing the E strategy & 0.7 \\
\hline$R_{i}$ & The income of professional managers when choosing the NE strategy & 0.1 \\
\hline$C_{d}$ & The cost of professional managers for making a great effort to manage the company & 0.4 \\
\hline$F$ & $\begin{array}{c}\text { The gain of professional managers which is the reputation gain when the strategy choices are }\{\mathrm{M}, \mathrm{E}\} \text { and the loss } \\
\text { when the strategy choices are }\{\mathrm{M}, \mathrm{NE}\}\end{array}$ & 0.05 \\
\hline
\end{tabular}

strategy, so the evolutionary equilibrium point is $\{M$, E\} as shown in Figure 16.

(6) The impact of $R_{d}$ on the evolutionary results: When $R_{d}$ is increasing, the difference between the expected payoffs of owners choosing the M strategy and NM strategy gradually increases, resulting in enterprise owners' hesitation in the process of strategy choices and the probability of choosing the M strategy gradually decreases as shown in Figure 17.
However, because the expected payoff of choosing the $M$ strategy is still greater than that of the NM strategy, the enterprise owners will eventually choose the $\mathrm{M}$ strategy. When $R_{d}$ gradually decreases from 0.7 to 0.4 , the probability of professional managers choosing the E strategy gradually decreases and eventually they choose the NE strategy; thus the evolutionary equilibrium point is $\{\mathrm{M}, \mathrm{NE}\}$. When $R_{d}$ gradually increases to 1.0 and the probability of professional managers choosing the E strategy 


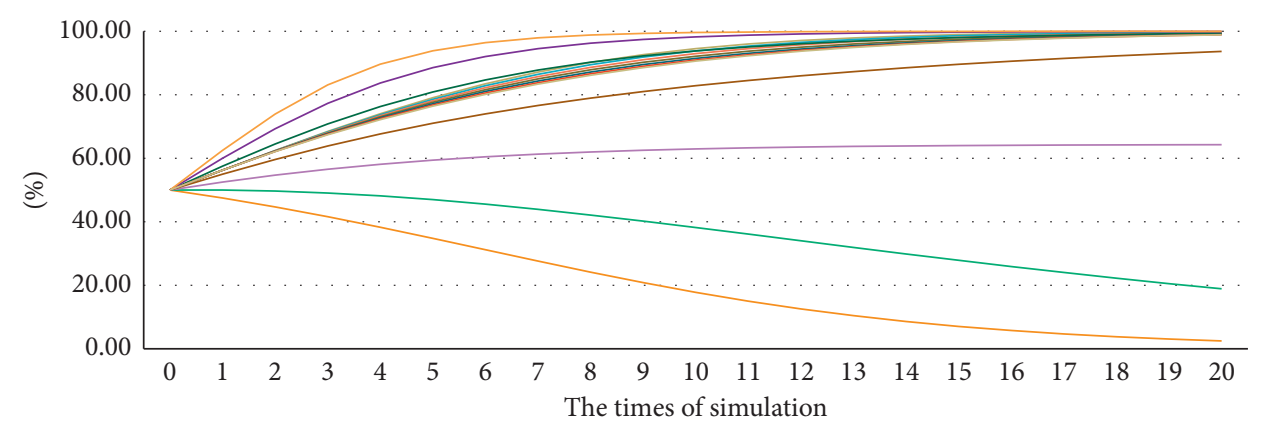

- The probability of enterprise owners choosing the M strategy $\left(R_{m}=1.2\right)$

- The probability of enterprise owners choosing the M strategy $\left(R_{m}=1.3\right)$

- The probability of enterprise owners choosing the M strategy $\left(R_{m}=1.4\right)$

- The probability of enterprise owners choosing the M strategy $\left(R_{m}=1.5\right)$

- The probability of enterprise owners choosing the M strategy $\left(R_{m}=1.6\right)$

— The probability of enterprise owners choosing the M strategy $\left(R_{m}=1.7\right)$

- The probability of enterprise owners choosing the M strategy $\left(R_{m}=1.8\right)$

- The probability of professional managers choosing the E strategy $\left(R_{m}=1.2\right)$

- The probability of professional managers choosing the E strategy $\left(R_{m}=1.3\right)$

- The probability of professional managers choosing the E strategy $\left(R_{m}=1.4\right)$

- The probability of professional managers choosing the E strategy $\left(R_{m}=1.5\right)$

- The probability of professional managers choosing the E strategy $\left(R_{m}=1.6\right)$

- The probability of professional managers choosing the E strategy $\left(R_{m}=1.7\right)$

The probability of professional managers choosing the E strategy $\left(R_{m}=1.8\right)$

FIgURE 12: The impact of $R_{m}$ on the evolutionary results.

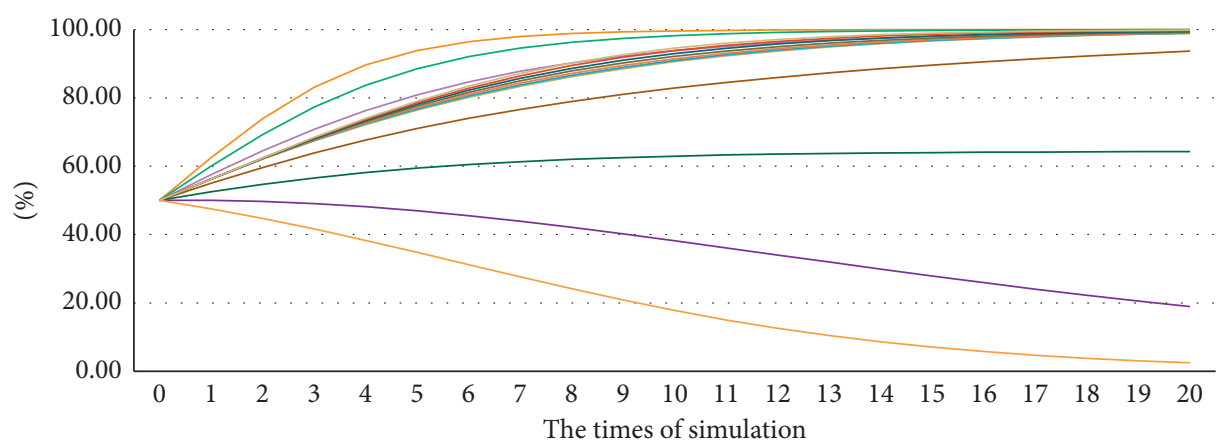

The probability of enterprise owners choosing the M strategy $\left(R_{u}=0.7\right)$
The probability of enterprise owners choosing the M strategy $\left(R_{u}=0.8\right)$
T The probability of enterprise owners choosing the M strategy $\left(R_{u}=0.9\right)$
T The probability of enterprise owners choosing the M strategy $\left(R_{u}=1.0\right)$
The probability of enterprise owners choosing the M strategy $\left(R_{u}=1.1\right)$
The probability of enterprise owners choosing the M strategy $\left(R_{u}=1.2\right)$
T The probability of enterprise owners choosing the M strategy $\left(R_{u}=1.3\right)$
The probability of professional managers choosing the E strategy $\left(R_{u}=0.7\right)$
The probability of professional managers choosing the E strategy $\left(R_{u}=0.8\right)$
The probability of professional managers choosing the E strategy $\left(R_{u}=0.9\right)$
The probability of professional managers choosing the E strategy $\left(R_{u}=1.0\right)$
The probability of professional managers choosing the E strategy $\left(R_{u}=1.1\right)$
The probability of professional managers choosing the E strategy $\left(R_{u}=1.2\right)$
The probability of professional managers choosing the E strategy $\left(R_{u}=1.3\right)$

FIGURE 13: The impact of $R_{u}$ on the evolutionary results.

increases, then professional managers will choose the E strategy and the evolutionary equilibrium point is $\{\mathrm{M}, \mathrm{E}\}$.

(7) The impact of $R_{i}$ on the evolutionary results:
When $R_{i}$ is increasing, the difference between the expected payoffs of the E strategy and NE strategy continues to decrease.Therefore the probability of professional managers choosing the E strategy 


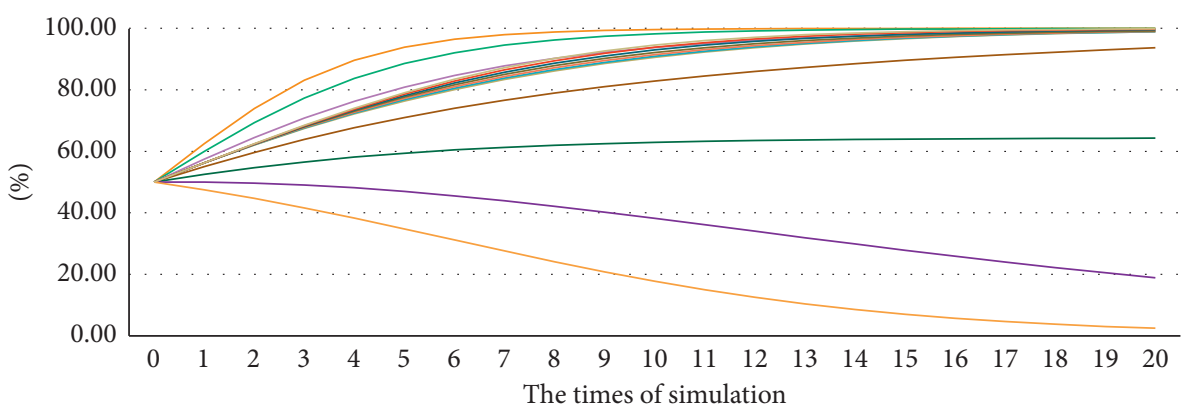

- The probability of enterprise owners choosing the M strategy $\left(C_{m}=0.1\right)$

- The probability of enterprise owners choosing the M strategy $\left(C_{m}=0.2\right)$

- The probability of enterprise owners choosing the M strategy $\left(C_{m}=0.3\right)$

- The probability of enterprise owners choosing the M strategy $\left(C_{m}=0.4\right)$

- The probability of enterprise owners choosing the M strategy $\left(C_{m}=0.5\right)$

- The probability of enterprise owners choosing the M strategy $\left(C_{m}=0.6\right)$

- The probability of enterprise owners choosing the M strategy $\left(C_{m}=0.7\right)$

- The probability of professional managers choosing the E strategy $\left(C_{m}=0.1\right)$

- The probability of professional managers choosing the E strategy $\left(C_{m}=0.2\right)$

- The probability of professional managers choosing the E strategy $\left(C_{m}=0.3\right)$

- The probability of professional managers choosing the E strategy $\left(C_{m}=0.4\right)$

- The probability of professional managers choosing the E strategy $\left(C_{m}=0.5\right)$

- The probability of professional managers choosing the E strategy $\left(C_{m}=0.6\right)$

- The probability of professional managers choosing the E strategy $\left(C_{m}=0.7\right)$

FIGURE 14: The impact of $C_{m}$ on the evolutionary results.

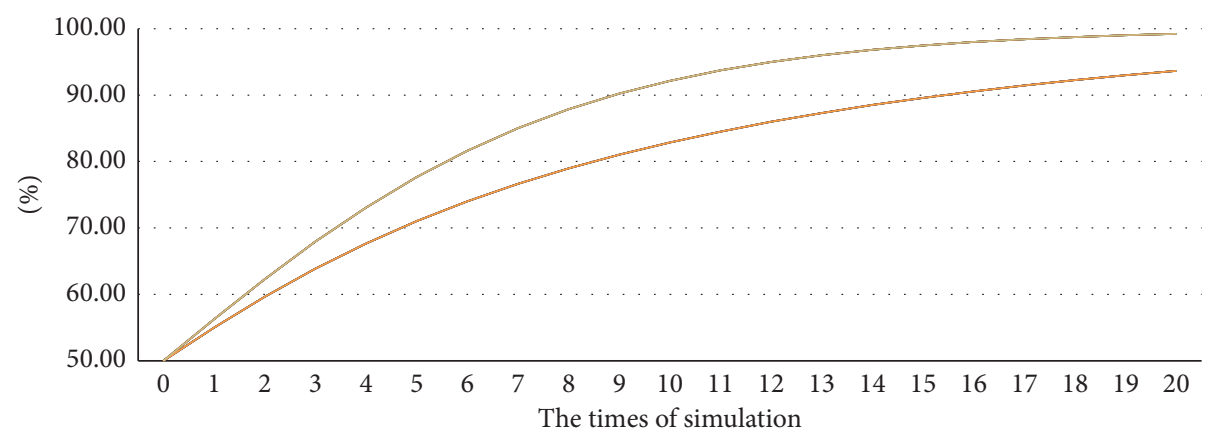

- The probability of enterprise owners choosing the M strategy $(T=0.15)$

- The probability of enterprise owners choosing the M strategy $(T=0.2)$

— The probability of enterprise owners choosing the M strategy $(T=0.25)$

- The probability of enterprise owners choosing the M strategy $(T=0.3)$

- The probability of enterprise owners choosing the M strategy $(T=0.35)$

- The probability of enterprise owners choosing the M strategy $(T=0.4)$

The probability of enterprise owners choosing the M strategy $(T=0.45)$

- The probability of professional managers choosing the E strategy $(T=0.15)$

_ The probability of professional managers choosing the E strategy $(T=0.2)$

- The probability of professional managers choosing the E strategy $(T=0.25)$

- The probability of professional managers choosing the E strategy $(T=0.3)$

- The probability of professional managers choosing the E strategy $(T=0.35)$

- The probability of professional managers choosing the E strategy $(T=0.4)$

_ The probability of professional managers choosing the E strategy $(T=0.45)$

FIgURE 15: The impact of $T$ on the evolutionary results.

decreases as shown in Figure 18. However, since the expected payoff of professional managers choosing the E strategy is greater than the expected payoff of choosing the NE strategy, professional managers will still choose the E strategy. In order to avoid the professional managers choosing the NE strategy, enterprise owners will gradually increase the probability of choosing the M strategy and the evolutionary equilibrium point is $\{\mathrm{M}, \mathrm{E}\}$.

(8) The impact of $C_{d}$ on the evolutionary results: 


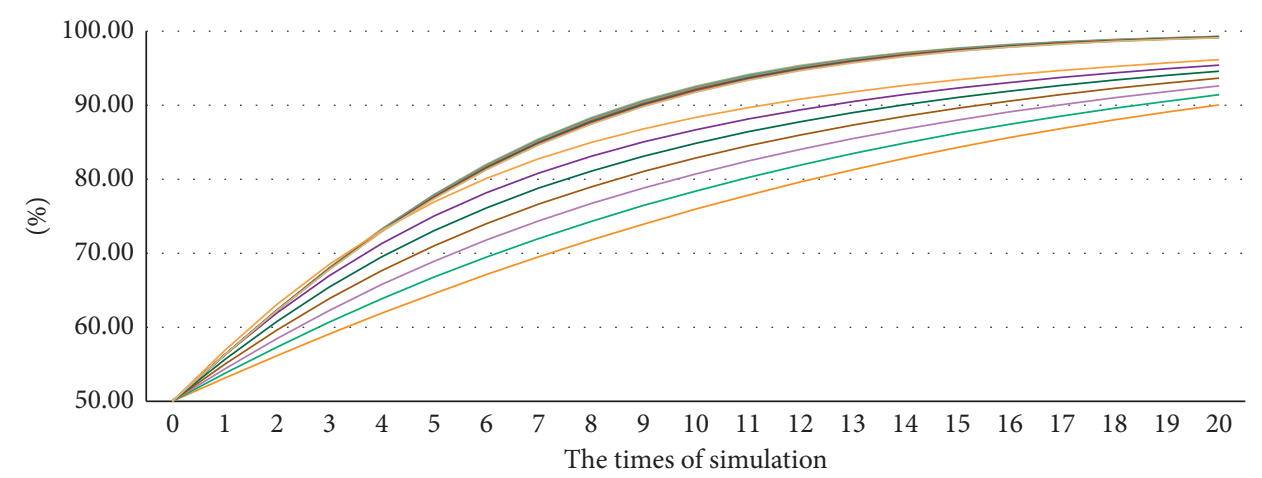

- The probability of enterprise owners choosing the M strategy $(S=0.05)$

— The probability of enterprise owners choosing the M strategy $(S=0.1)$

- The probability of enterprise owners choosing the M strategy $(S=0.15)$

- The probability of enterprise owners choosing the M strategy $(S=0.2)$

- The probability of enterprise owners choosing the M strategy $(S=0.25)$

- The probability of enterprise owners choosing the M strategy $(S=0.3)$

- The probability of enterprise owners choosing the M strategy $(S=0.35)$

- The probability of professional managers choosing the E strategy $(S=0.05)$

— The probability of professional managers choosing the E strategy $(S=0.1)$

- The probability of professional managers choosing the E strategy $(S=0.15)$

— The probability of professional managers choosing the E strategy $(S=0.2)$

- The probability of professional managers choosing the E strategy $(S=0.25)$

- The probability of professional managers choosing the E strategy $(S=0.3)$

- The probability of professional managers choosing the E strategy $(S=0.35)$

Figure 16: The impact of (S) on the evolutionary results.

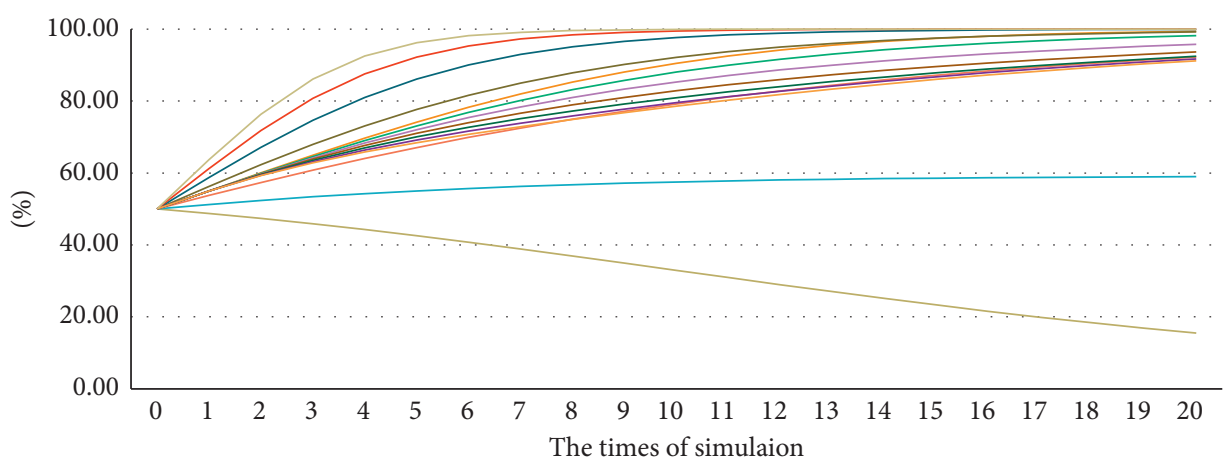

The probability of enterprise owners choosing the M strategy $\left(R_{d}=0.4\right)$

- The probability of enterprise owners choosing the M strategy $\left(R_{d}=0.5\right)$

— The probability of enterprise owners choosing the M strategy $\left(R_{d}=0.6\right)$

- The probability of enterprise owners choosing the M strategy $\left(R_{d}=0.7\right)$

— The probability of enterprise owners choosing the M strategy $\left(R_{d}=0.8\right)$

- The probability of enterprise owners choosing the M strategy $\left(R_{d}=0.9\right)$

- The probability of enterprise owners choosing the M strategy $\left(R_{d}=1.0\right)$

— The probability of professional managers choosing the E strategy $\left(R_{d}=0.4\right)$

- The probability of professional managers choosing the E strategy $\left(R_{d}=0.5\right)$

— The probability of professional managers choosing the E strategy $\left(R_{d}=0.6\right)$

- The probability of professional managers choosing the E strategy $\left(R_{d}=0.7\right)$

- The probability of professional managers choosing the E strategy $\left(R_{d}=0.8\right)$

— The probability of professional managers choosing the E strategy $\left(R_{d}=0.9\right)$

- The probability of professional managers choosing the E strategy $\left(R_{d}=1.0\right)$

Figure 17: The impact of $R_{d}$ on the evolutionary results. 
When $C_{d}$ is increasing, the payoff of choosing the M strategy is greater than that of the NM strategy for enterprise owners, and in order to avoid the professional managers choosing the NE strategy, they will gradually increase the probability of the $M$ strategy and eventually choose the $M$ strategy as shown in Figure 19. When $C_{d}$ decreases from 0.4 to 0.1 , the probability of professional managers choosing the E strategy increases continuously and finally they choose the E strategy, and the evolutionary equilibrium point is $\{\mathrm{M}, \mathrm{E}\}$. When $C_{d}$ gradually rises to 0.7 , the probability of professional managers choosing the NE strategy gradually increases and finally they choose the NE strategy, and the evolutionary equilibrium point is $\{\mathrm{M}, \mathrm{NE}\}$.

(9) The impact of $F$ on the evolutionary results:

When $F$ is increasing, professional managers will be more inclined to choose the E strategy. As the difference between the expected payoffs of enterprise owners choosing the $M$ strategy and NM strategy decreases gradually, resulting in the hesitation of enterprise owners in the process of strategy choices, the probability of choosing the $M$ strategy is gradually decreasing in each simulation as shown in Figure 20. However, because the expected payoff of choosing the M strategy is still greater than that of the NM strategy, the enterprise owners will eventually choose the $M$ strategy, and the evolutionary equilibrium point is $\{\mathrm{M}, \mathrm{E}\}$.

In summary, the impact of evolutionary variables on the strategy choices of enterprise owners and professional managers is shown in Table 8 .

\section{Discussion}

Based on the perspective of dynamic evolutionary game theory, the authors constructed a dynamic evolutionary game model of strategy choice between enterprise owners and professional managers, explored the strategic choice behavior and evolutionary path of enterprise owners and professional managers in 18 situations, discussed the strategic choices and evolution path of different scenarios, and simulated the sensitivity of evolutionary parameters. The paper shows that, as a bounded rational stakeholder, the main decisive factor of making choices for both the principal (enterprise owners) and the agent (professional managers) under the asymmetric information scenario is their expected payoffs.

The dynamic simulation analysis shows that the strategic choices of enterprise owners and professional managers have the following characteristics: The probability of strategy choice set $\{M, E\}$ will increase with the profit of $M$ and $E$ strategy and decrease with that of the NM and NE strategy. An increase in cooperation costs will improve the probability of strategy choice set $\{\mathrm{NM}, \mathrm{NE}\}$, but the change of extra profit T of enterprise owners does not affect the evolutionary results. In addition, high reputation gain or loss $\mathrm{F}$ will increase the probability of professional managers choosing the E strategy.
Therefore, the key to improving the relationship of principal and agent is perfecting the incentive-compatibility mechanism, such as increasing the payoff if both parties choose to cooperate, changing the preferences of individuals during the decision-making process [46]. In addition, information asymmetry will lead to adverse selection by both parties. Therefore, it is necessary to further improve the managerial labor market for reduced information asymmetry and promote long-term effective cooperation between the two parties.

Firstly, there is obvious asymmetric information between the professional managers and the enterprise owners, which is the root cause of the principal-agent problem [47]. The factor endowment and information channel of professional managers are better than those of enterprise owners [48], so they have obvious information advantages. Due to limited access to information, the principal cannot collect all the information about efforts of their agents and design an effective incentive contract. Therefore, enterprises need to create an effective information transmission mechanism to improve transmission ability and solve the information asymmetry problem.

Secondly, improve the income of cooperation and reduce that of speculation. The simulation analysis shows that the probability of both sides choosing a strategy is positively related to the payoff of the strategy. Therefore, the enterprise should introduce the performance commission reward which is related to the manager's long-term benefit of the enterprise and establish an incentive mechanism through stocks to bind the interests of both parties [49]. In addition, the income of speculation can be reduced by strengthening corporate governance, improving internal control system, and establishing strict supervision and whistle-blowing mechanisms.

Thirdly, reduce the cost of cooperation. The probability of both sides choosing cooperation is inversely proportional to the costs of monitoring or making an effort [50]. Therefore, enterprises should ensure the legitimate and transparency operation to reduce the costs of professional managers. In addition, owners should trust professional managers and create an environment to help them work conscientiously to maximize the value of the company [51].

Fourthly, standardize the managerial labor market and expand the impact of reputation gains and losses. The reputation gain with a nonmonetary incentive is beneficial to promote professional managers to work conscientiously. In addition, the increase of reputation loss can increase the speculative risk and restrain the speculative behavior of professional managers [52]. The managerial labor market should be constantly standardized by establishing and improving integrity policies, increasing punishment for breach of faith, and maintaining the punishment of speculation.

Fifthly, improve principal-agent cooperation by the principal's appropriate supervision. On the one hand, the strategy choices of the professional managers depend on the probability of the enterprise owners' choices. On the other hand, professional managers will suffer the loss of reputation if the owners choose to supervise, which will increase their 


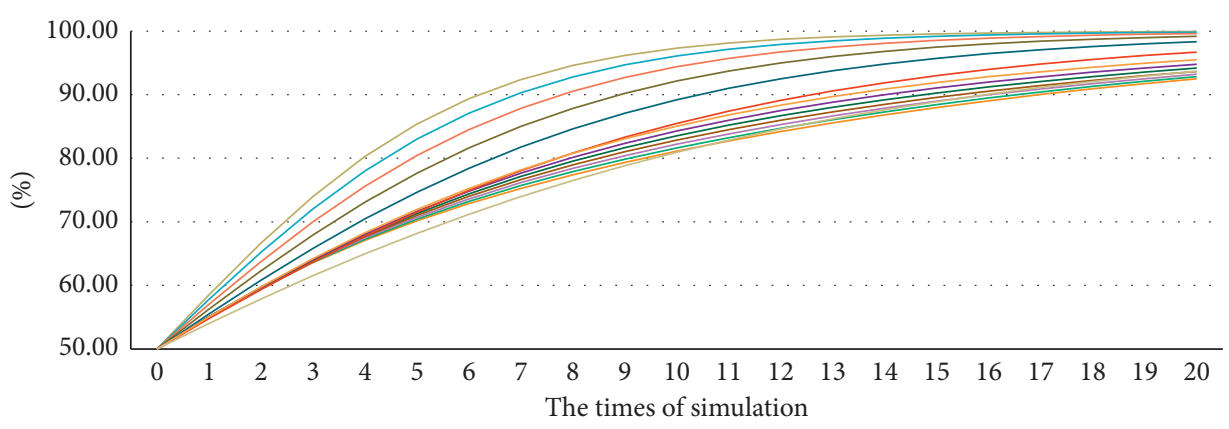

- The probability of enterprise owners choosing the M strategy $\left(R_{i}=0.01\right)$

— The probability of enterprise owners choosing the M strategy $\left(R_{i}=0.04\right)$

— The probability of enterprise owners choosing the M strategy $\left(R_{i}=0.07\right)$

— The probability of enterprise owners choosing the M strategy $\left(R_{i}=0.1\right)$

- The probability of enterprise owners choosing the M strategy $\left(R_{i}=0.13\right)$

- The probability of enterprise owners choosing the M strategy $\left(R_{i}=0.16\right)$

- The probability of enterprise owners choosing the M strategy $\left(R_{i}=0.19\right)$

- The probability of professional managers choosing the E strategy $\left(R_{i}=0.01\right)$

- The probability of professional managers choosing the E strategy $\left(R_{i}=0.04\right)$

- The probability of professional managers choosing the E strategy $\left(R_{i}=0.07\right)$

— The probability of professional managers choosing the E strategy $\left(R_{i}=0.1\right)$

- The probability of professional managers choosing the E strategy $\left(R_{i}=0.13\right)$

- The probability of professional managers choosing the E strategy $\left(R_{i}=0.16\right)$

_ The probability of professional managers choosing the E strategy $\left(R_{i}=0.19\right)$

FIgURE 18: The impact of $R_{i}$ on the evolutionary results.

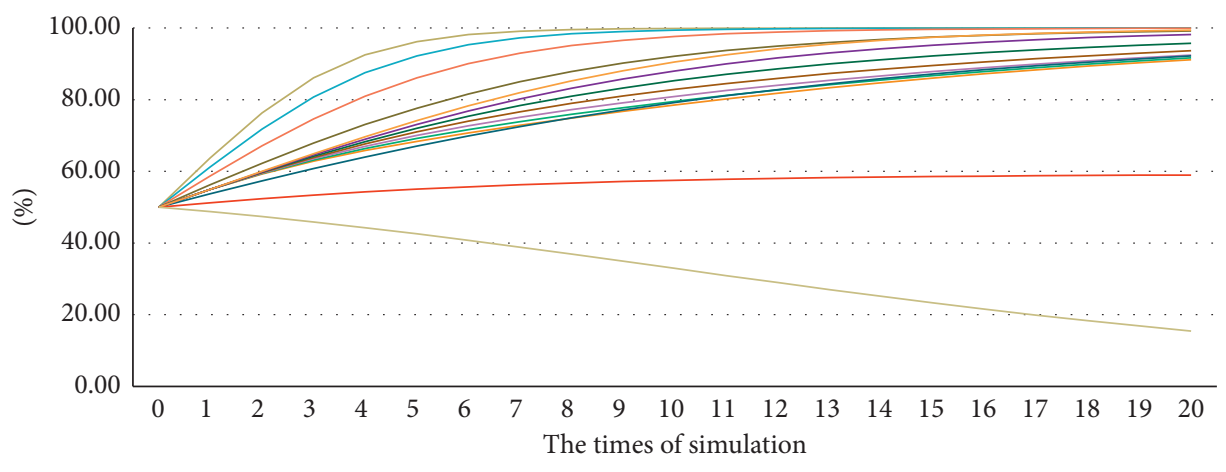

The probability of enterprise owners choosing the M strategy $\left(C_{d}=0.1\right)$
The probability of enterprise owners choosing the M strategy $\left(C_{d}=0.2\right)$
The probability of enterprise owners choosing the M strategy $\left(C_{d}=0.3\right)$
T The probability of enterprise owners choosing the M strategy $\left(C_{d}=0.4\right)$
The probability of enterprise owners choosing the M strategy $\left(C_{d}=0.5\right)$
The probability of enterprise owners choosing the M strategy $\left(C_{d}=0.6\right)$
The probability of enterprise owners choosing the M strategy $\left(C_{d}=0.7\right)$
The probability of professional managers choosing the E strategy $\left(C_{d}=0.1\right)$
The probability of professional managers choosing the E strategy $\left(C_{d}=0.2\right)$
The probability of professional managers choosing the E strategy $\left(C_{d}=0.3\right)$
The probability of professional managers choosing the E strategy $\left(C_{d}=0.4\right)$
The probability of professional managers choosing the E strategy $\left(C_{d}=0.5\right)$
The probability of professional managers choosing the E strategy $\left(C_{d}=0.6\right)$
The probability of professional managers choosing the E strategy $\left(C_{d}=0.7\right)$

FIgURE 19: The impact of $C_{d}$ on the evolutionary results.

speculative costs and prevent speculative behaviors [53]. The higher the supervision cost the owners pay, the greater the possibility of professional managers choosing to work conscientiously. Therefore, enterprise owners should improve supervision input and implement effective supervision measures to prompt professional managers to work 


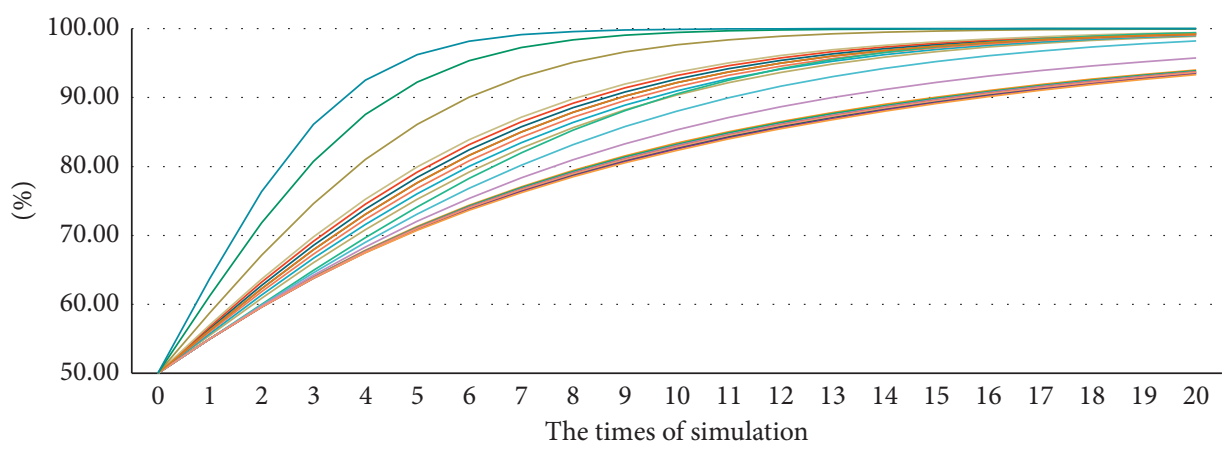

- The probability of enterprise owners choosing the M strategy $(F=0.02)$

- The probability of enterprise ownerschoosing the M strategy $(F=0.03)$

- The probability of enterprise owners choosing the M strategy $(F=0.04)$

- The probability of enterprise owners choosing the M strategy $(F=0.05)$

- The probability of enterprise owners choosing the M strategy $(F=0.06)$

- The probability of enterprise owners choosing the M strategy $(F=0.07)$

_ The probability of enterprise owners choosing the M strategy $(F=0.08)$

- The probability of professional managers choosing the E strategy $(F=0.02)$

- The probability of professional managers choosing the E strategy $(F=0.03)$

- The probability of professional managers choosing the E strategy $(F=0.04)$

- The probability of professional managers choosing the E strategy $(F=0.05)$

- The probability of professional managers choosing the E strategy $(F=0.06)$

- The probability of professional managers choosing the E strategy $(F=0.07)$

_ The probability of professional managers choosing the E strategy $(F=0.08)$

Figure 20: The impact of (F) on the evolutionary results.

TABLE 8: The influence of variables on the strategy choices.

\begin{tabular}{lcc}
\hline Variables & The probability of enterprise owners choosing the M strategy & The probability of professional managers choosing the E strategy \\
\hline$R_{m}$ & Positive correlation & Partial negative correlation \\
$R_{u}$ & Negative correlation & Partial positive correlation \\
$C_{m}$ & Negative correlation & Partial negative correlation \\
$T$ & No effect & No effect \\
$S$ & Positive correlation & No effect \\
$R_{d}$ & Partial negative correlation & Positive correlation \\
$R_{i}$ & Partial positive correlation & Negative correlation \\
$C_{d}$ & Partial positive correlation & Negative correlation \\
$F$ & Partial negative correlation & Positive correlation \\
\hline
\end{tabular}

conscientiously. However, enterprise owners should adopt appropriate supervision regularly, since the supervision does not always have a positive effect on the results of cooperation.

In summary, the principal-agent cooperation of enterprises needs proper supervision and guidance with incentive for the company to maximize its value [54]. The key is to design an incentive and restraint mechanism which can not only induce various stakeholders to choose correct choices but also effectively standardize the behavior of professional managers. In addition to the conventional incentive methods such as equity incentive and performance remuneration, the establishment of agent reputation and promotion mechanisms is also an effective way to improve the principal-agent relationship [55]. Furthermore, standardization of the managerial labor market and increasing the impact of reputation gains and losses are necessary to promote cooperation and achieve win-win results.

\section{Conclusion}

In this paper, the authors focused on the characteristics of the decision-making behaviors between enterprise owners and professional managers, analyzed the principal-agent problem between enterprise owners and professional managers using system dynamics, evolutionary game and principal-agent theory, discussed the evolution of both parties' strategic behaviors under 18 different scenarios, simulated the impacts of different factors on strategy selection and behavioral evolution, and provided a theoretical basis for resolving the principal-agent problem.

The keys to solving the principal-agent problem and improving the corporate governance are changing the expected payoffs of different strategy choices and the asymmetric status. The targeted suggestions for the principalagent problem can conclude as follows: Firstly, improve internal information channels and design transmission mechanisms to eliminate the influence of information 
asymmetry between the principal and agent, which is a precondition for improving the principal-agent relationship. Secondly, increase profit and reduce the cost to increase the profit of cooperation through compliance and mutual trust. Thirdly, standardize the managerial labor market and expand the impact of reputation gains and losses to encourage professional managers to work conscientiously. Fourthly, use monetary and nonmonetary incentives and increase the intensity of punishment to promote the consistency of the goals of principal and agent. Fifthly, adopt appropriate supervision of enterprise owners to improve the outcome of principal-agent cooperation, which should consider the impact of differences in expected payoffs of different strategies.

The results of this paper are important for the ongoing efforts to improve the principal-agent relationship. However, as we mainly focus on the conflict of interests and the characteristics of strategic choices between the principal and agent, the company's profit is not connected with the payoff function of the individuals. Therefore, further studies are necessary to associate the payoff of the stakeholders with company's profit for more accurate modeling and consider additional scenarios in the simulation analysis.

\section{Data Availability}

The data used to support the findings of this study are available from the corresponding author upon request.

\section{Conflicts of Interest}

The authors declare no conflicts of interest.

\section{Authors' Contributions}

Liang Yuan and Xiaorui Tao contributed equally to this work.

\section{Acknowledgments}

This study was supported by the Center for Reservoir Resettlement, China Three Gorges University (No. 2019KQ01).

\section{Supplementary Materials}

The stable states of partial equilibrium points for (1)-(18) scenarios are given. (Supplementary Materials)

\section{References}

[1] S. J. Grossman and O. D. Hart, "An analysis of the principalagent problem," Econometrica, vol. 51, no. 1, p. 7, 1983.

[2] E. F. Fama and M. C. Jensen, "Separation of ownership and control," The Journal of Law and Economics, vol. 26, no. 2, pp. 301-325, 1983.

[3] R. K. Aggarwal and A. A. Samwick, "The other side of the trade-off: the impact of risk on executive compensation," Journal of Political Economy, vol. 107, no. 1, pp. 65-105, 1999.
[4] M. Maggetti and Y. Papadopoulos, "The principal-agent framework and independent regulatory agencies," Political Studies Review, vol. 16, no. 3, pp. 172-183, 2018.

[5] P. M. Healy and K. G. Palepu, "Information asymmetry, corporate disclosure, and the capital markets: a review of the empirical disclosure literature," Journal of Accounting and Economics, vol. 31, no. 1-3, pp. 405-440, 2001.

[6] R. W. Waterman and K. J. Meier, "Principal-agent models: an expansion?" Journal of Public Administration Research and Theory, vol. 8, no. 2, pp. 173-202, 1998.

[7] R. Wilson, The Structure of Incentive for Decentralization under Uncertainty, La Decision, Paris, France, 1969.

[8] M. Spence and R. Zeckhauser, "Insurance, information and individual action," in Uncertainty in Economics, pp. 333-343, Elsevier, Amsterdam, Netherlands, 1978.

[9] S. A. Ross, "The economic theory of agency: the principal's problem," American Economic Review, vol. 63, no. 2, pp. 134-139, 1973.

[10] J. A. Mirrlees, The Theory of Moral Hazard and Unobservable Behavior: Part I, Nuffield College, Oxford, UK, 1999.

[11] B. Holmstrom, "Moral hazard and observability," The Bell Journal of Economics, vol. 10, no. 1, pp. 74-91, 1979.

[12] J. Cvitanić, D. Possamaï, and N. Touzi, "Dynamic programming approach to principal-agent problems," Finance and Stochastics, vol. 22, no. 1, pp. 1-37, 2018.

[13] I. Gilboa and D. Schmeidler, "Maxmin expected utility with non-unique prior," Journal of Mathematical Economics, vol. 18, no. 2, pp. 141-153, 1989.

[14] I. Rasul and S. Sonderegger, "The role of the agent's outside options in principal-agent relationships," Games and Economic Behavior, vol. 68, no. 2, pp. 781-788, 2010.

[15] R. Silvers, "The value of information in a principal-agent model with moral hazard: the ex post contracting case," Games and Economic Behavior, vol. 74, no. 1, pp. 352-365, 2012.

[16] C. Helm and F. Wirl, "The principal-agent model with multilateral externalities: an application to climate agreements," Journal of Environmental Economics and Management, vol. 67, no. 2, pp. 141-154, 2014.

[17] M. Bichler and P. Paulsen, "A principal-agent model of bidding firms in multi-unit auctions," Games and Economic Behavior, vol. 111, pp. 20-40, 2018.

[18] K. Uğurlu, "Dynamic optimal contract under parameter uncertainty with risk-averse agent and principal," Turkish Journal of Mathematics, vol. 42, no. 3, pp. 977-992, 2018.

[19] D. Chaney, "A principal-agent perspective on consumer coproduction: crowdfunding and the redefinition of consumer power," Technological Forecasting and Social Change, vol. 141, pp. 74-84, 2019.

[20] J. Schosser, "Consistency between principal and agent with differing time horizons: computing incentives under risk," European Journal of Operational Research, vol. 277, no. 3, pp. 1113-1123, 2019.

[21] D.-q. Sun, X.-y. Ma, D.-j. Wang, and J.-j. Li, "Principal-agent problem for returns handling in a reverse supply chain with one manufacturer and two competing dealers," Applied Mathematical Modelling, vol. 66, pp. 118-140, 2019.

[22] J.-W. Chang, "Monitoring and competing principals: a double-edged sword," Journal of Economic Theory, vol. 189, Article ID 105101, 2020.

[23] Y. Wang, W. Huang, B. Liu, and X. Zhang, "Optimal effort in the principal-agent problem with time-inconsistent preferences," The North American Journal of Economics and Finance, vol. 52, Article ID 100909, 2020. 
[24] M. Königstein, J. Kovács, and E. Zala-Mezö, "Fairness in a one-principal-two-agents game - a post-experimental questionnaire analysis," Journal of Economic Psychology, vol. 24, no. 4, pp. 491-503, 2003.

[25] C. Keser and M. Willinger, "Theories of behavior in principalagent relationships with hidden action," European Economic Review, vol. 51, no. 6, pp. 1514-1533, 2007.

[26] U. Leopold-Wildburger and A. Mietek, "Bonus or flat wage? An experiment into the principal-agent problem," Applied Mathematics and Computation, vol. 217, no. 3, pp. 1141-1149, 2010.

[27] B. Corgnet, J. Gómez-Miñambres, and R. Hernán-González, "Goal setting in the principal-agent model: weak incentives for strong performance," Games and Economic Behavior, vol. 109, pp. 311-326, 2018.

[28] T. Flannery and S. Roberts, "The use of non-monotonic contracts in a single period game: an experimental investigation," Journal of Behavioral and Experimental Economics, vol. 77, pp. 177-185, 2018.

[29] J. Rubin and R. Sheremeta, "Principal-agent settings with random shocks," Management Science, vol. 62, no. 4, pp. 985-999, 2016.

[30] O. A. Rud, J. P. Rabanal, and J. Horowitz, "Does competition aggravate moral hazard? A Multi-Principal-Agent experiment," Journal of Financial Intermediation, vol. 33, pp. 115121, 2018.

[31] K. Hausken, "Principal-agent theory, game theory, and the precautionary principle," Decision Analysis, vol. 16, no. 2, pp. 105-127, 2019.

[32] D. Gong, M. Tang, S. Liu, and Q. Li, “A reconsidering production coordination: a principal-agent theory-based analysis," Advances in Production Engineering \& Management, vol. 12, no. 1, pp. 51-61, 2017.

[33] P. D. Azar and S. Micali, "Computational principal-agent problems," Theoretical Economics, vol. 13, no. 2, pp. 553-578, 2018.

[34] C. Kellner, "The principal-agent problem with smooth ambiguity," Review of Economic Design, vol. 21, no. 2, pp. 83-119, 2017.

[35] D. Páez-Pérez and M. Sánchez-Silva, “A dynamic principalagent framework for modeling the performance of infrastructure," European Journal of Operational Research, vol. 254, no. 2, pp. 576-594, 2016.

[36] O. Kadan, P. J. Reny, and J. M. Swinkels, "Existence of optimal mechanisms in principal-agent problems," Econometrica, vol. 85, no. 3, pp. 769-823, 2017.

[37] D. Ni, X. Wang, and K. Zheng, "Triggering reciprocity in a principal-agent game,” SSRN Electronic Journal, 2018.

[38] L. Yuan, W. He, Z. Liao et al., "Allocating water in the Mekong river basin during the dry season," Water, vol. 11, no. 2, p. 400, 2019.

[39] D. M. Degefu, W. He, L. Yuan, and J. H. Zhao, "Water allocation in transboundary river basins under water scarcity: a cooperative bargaining approach," Water Resources Management, vol. 30, no. 12, pp. 4451-4466, 2016.

[40] E. F. Fama, "Agency problems and the theory of the firm," Journal of Political Economy, vol. 88, no. 2, pp. 288-307, 1980.

[41] D. Friedman, "Evolutionary games in economics," Econometrica, vol. 59, no. 3, pp. 637-666, 1991.

[42] D. Friedman, "Evolutionary economics goes mainstream: a review of the theory of learning in games," Journal of Evolutionary Economics, vol. 8, no. 4, pp. 423-432, 1998.

[43] Q. Gao, P. Wang, L. L. Guo, J. Jiang, X. Liu, and Y. Wang, "Study on the environmental risk communication model for trans-boundary water pollution based on multi-agent," in Proceedings of the 2011 Second International Conference on Mechanic Automation and Control Engineering, pp. 61736176, Inner Mongolia, China, July 2011.

[44] L. Yuan, W. He, D. M. Degefu et al., "Transboundary water sharing problem; a theoretical analysis using evolutionary game and system dynamics," Journal of Hydrology, vol. 582, Article ID 124521, 2020.

[45] L. Yuan, W. He, D. M. Degefu, Z. Wan, T. S. Ramsey, and $\mathrm{X}$. $\mathrm{Wu}$, "A system dynamics simulation model for water conflicts in the Zhanghe river basin, China," International Journal of Water Resources Development, pp. 1-17, 2021.

[46] F. Wu and J. Ma, "The complex dynamics of a multi-product mixed duopoly model with partial privatization and crossownership," Nonlinear Dynamics, vol. 80, no. 3, pp. 1391-1401, 2015.

[47] M. Popovic, M. Kuzmanovic, and B. Andric Gusavac, "The agency dilemma : information asymmetry in the "principalagent" problem," Management-Journal for Theory and Practice of Management, vol. 17, no. 62, pp. 13-22, 2012.

[48] Z. Houhamdi, B. Athamena, and G. El Refae, "Managing asymmetric information effects in decision-making productivity-based model," International Journal of Knowledge and Systems Science, vol. 11, no. 2, pp. 86-107, 2020.

[49] Y. Kong, W. He, L. Yuan et al., "Decoupling economic growth from water consumption in the Yangtze river economic belt, China," Ecological Indicators, vol. 123, pp. 107344-202144, 2021.

[50] X. Gao, J. Shen, W. He et al., "Multilevel governments' decision-making process and its influencing factors in watershed ecological compensation," Sustainability, vol. 11, no. 7, p. 1990, 2019.

[51] F. Wu and J. Ma, "The equilibrium, complexity analysis and control in epiphytic supply chain with product horizontal diversification," Nonlinear Dynamics, vol. 93, no. 4, pp. 2145-2158, 2018.

[52] L. Xie, J. Ma, and M. Goh, "Supply chain coordination in the presence of uncertain yield and demand," International Journal of Production Research, vol. 59, no. 14, pp. 4342-4358, 2020.

[53] B. Bao, J. Ma, and M. Goh, "Short- and long-term repeated game behaviours of two parallel supply chains based on government subsidy in the vehicle market," International Journal of Production Research, vol. 58, no. 24, pp. 7507-7530, 2020.

[54] J. Ma, Y. Hou, W. Yang, and Y. Tian, “A time-based pricing game in a competitive vehicle market regarding the intervention of carbon emission reduction," Energy Policy, vol. 142, Article ID 111440, 2020.

[55] J. Ma, Y. Hou, Z. Wang, and W. Yang, "Pricing strategy and coordination of automobile manufacturers based on government intervention and carbon emission reduction," Energy Policy, vol. 148, Article ID 111919, 2021. 